\title{
NATIVE SMALL MAMMAL USE OF AN INVASIVE GRASS: HEERMANN'S KANGAROO RATS (DIPODOMYS HEERMANNI) AND VELDT GRASS (EHRHARTA CALYCINA) IN COASTAL CALIFORNIA
}

\author{
A Thesis \\ presented to \\ the Faculty of California Polytechnic State University, \\ San Luis Obispo
}

In Partial Fulfillment

of the Requirements for the Degree

Master of Science in Biological Sciences

by

Juliana Trunzo

March 2015 
(C) 2015

Juliana Trunzo

ALL RIGHTS RESERVED 
TITLE:

AUTHOR:

DATE SUBMITTED:

COMMITTEE CHAIR:

COMMITTEE MEMBER:

COMMITTEE MEMBER:
Native Small Mammal Use of an Invasive Grass:

Heermann's Kangaroo Rats (Dipodomys

heermanni) and Veldt Grass (Ehrharta calycina) in Coastal California

Juliana Trunzo

March 2015

Francis Villablanca, Ph.D.

Professor of Biological Sciences

Gita Kolluru, Ph.D.

Associate Professor of Biological Sciences

Sean Lema, Ph.D.

Assistant Professor of Biological Sciences 


\begin{abstract}
Native Small Mammal Use of an Invasive Grass: Heermann's Kangaroo Rats (Dipodomys heermanni) and Veldt Grass (Ehrharta calycina) in Coastal California
\end{abstract}

\title{
Juliana Trunzo
}

Invasive species are generally regarded as detrimental to native communities because they cause increased competition and community structure alterations. There is therefore a critical need to understand the ecological processes underlying the establishment and spread of invasive species. While most studies to date have focused on the role of competition in species invasions, trophic dynamics may also play a fundamental role in the establishment and spread of non-natives, especially in cases when a non-native species experiences differential predation pressure relative to a native competitor. Herein I explore the potential for differential granivory pressure by a native rodent (Heermann's kangaroo rat, Dipodomys heermanni arenae) on native shrubs and an invasive plant (Veldt grass, Ehrharta calycina). Veldt grass, a perennial tufted grass native to South Africa and introduced to California in 1929, is highly invasive, and the shift of native coastal dune scrub to a grassland, dominated by Veldt grass, is considered one of the factors that led to the decline of the federally endangered Morro Bay kangaroo rat. However, kangaroo rats are largely graminivores (consume grass seed) and are known to consume invasive grasses and other plants. Differential seed preferences for native and Veldt seed were examined by placing feeding stations containing each seed type in habitats dominated by either native plants or Veldt grass. Each feeding station was monitored using motion-activated game cameras and the amount of each seed type collected by nineteen individually-marked, wild kangaroo rats was documented. These marked kangaroo rats were monitored both in native and Veldt grass habitats, allowing for the testing of habitat origin (Native vs. Veldt), sex (male or female) and seed type on the amount of seed taken. Nine of the kangaroo rats harvested Veldt grass seed. Though females collected more seed than males, there was no difference between the amounts ( $\%$ of available seed) of Veldt grass and native seed collected. Habitat of origin (i.e., habitats with Veldt grass present or habitats without Veldt grass) had no effect on the amount of seed collected or the type of seed collected. During seed station trials, kangaroo rats were also recorded removing seed heads from naturally occurring Veldt grass stalks, providing clear documentation that Heermann's kangaroo rats do collect Veldt grass seed. Accompanying laboratory seed preference trials were also conducted to confirm the consumption of Veldt grass seed. These controlled laboratory trials revealed that Heermann's kangaroo rats will consume Veldt grass seed, although Veldt grass seed was consumed in smaller amounts (g) than millet and sunflower seed, which were presented simultaneously. These findings indicate that non-native Veldt grass may provide an additional or alternative source of seed for kangaroo rats, which could provide a partial explanation for why kangaroo rats are able to survive in monocultures of Veldt grass. 


\section{ACKNOWLEDGMENTS}

I am greatly appreciative for all of the support, encouragement, and guidance provided by my fellow students and the faculty and staff of the Biological Sciences Department at California Polytechnic State University, San Luis Obispo, CA. This process would not have been possible without your humor, kind words, and positive attitudes. Francis Villablanca deserves exceptional recognition for supporting me through this process, providing valuable advice, and continuously encouraging me and pushing me to my highest potential. In addition, I am thankful for the resources, facilities, College Based Funds, and the Aryan Roest Memorial Scholarship provided by California Polytechnic State University, San Luis Obispo, CA.

This work would not have been possible without the help of the exceptional undergraduate students that assisted me both in the lab and the field. I am grateful for all of the long and sometimes exhausting hours that you contributed to my project. Your enthusiasm and support made the early mornings, late nights, and tough work enjoyable.

I am forever grateful for the love and emotional support I have received from family and friends throughout my academic career. Your constant love and support has carried me through this process. 


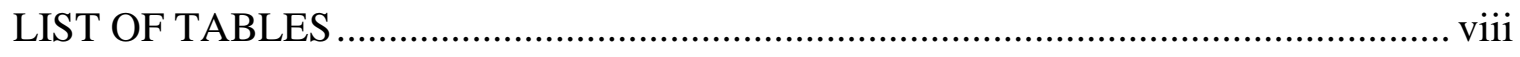

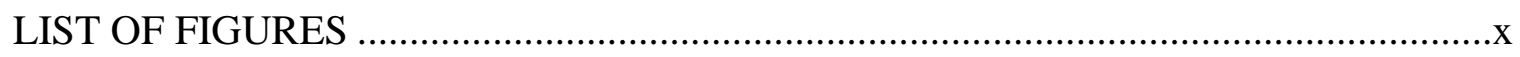

CHAPTER

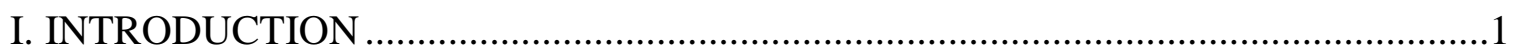

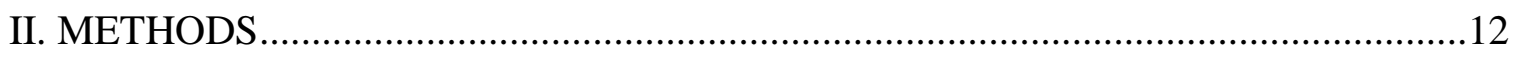

Experiment 1: Observations of Veldt and native seed collection in the field ............12

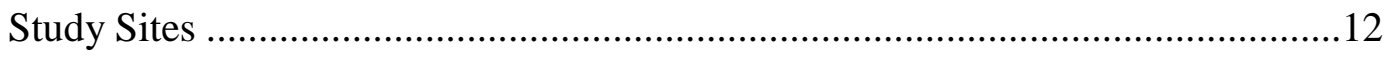

Study Animals: Live trapping and individual marks ......................................13

Seed box for foraging (seed-take) trials ......................................................... 14

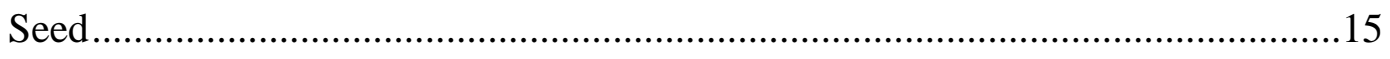

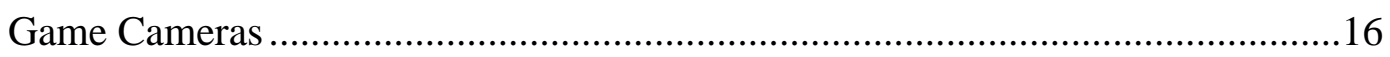

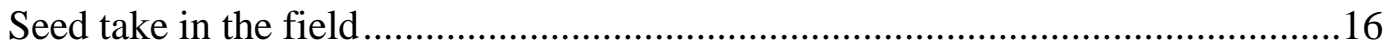

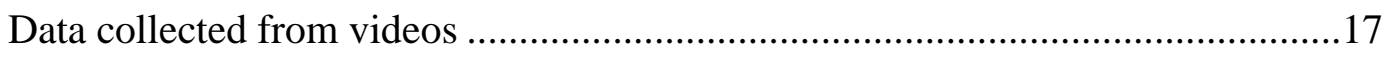

Data analysis methods for video data ...................................................... 19

Summary Statistics..................................................................19

Effects of sex, seed type, site type or interactions -

Repeated Measures ANOVA ..............................................................19

Effects of prior experience on subsequent experience...........................21

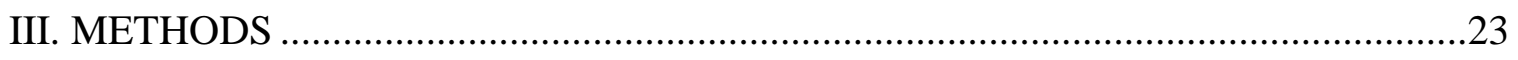

Experiment 2: Controlled Laboratory Veldt seed consumption test ........................23

Source population for captive seed consumption trials ...................................23

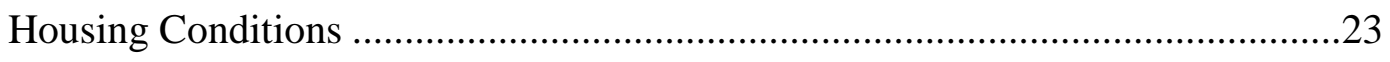

Husbandry and lab maintenance cycles/schedules ...........................................24

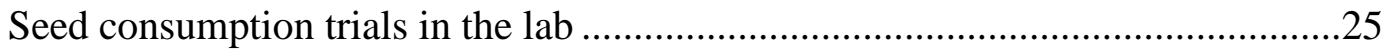

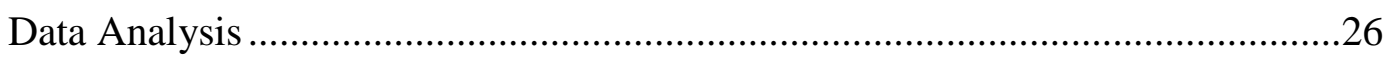

Seed consumption: day, seed type and interactions -

Repeated Measures ANOVA ...........................................................26 


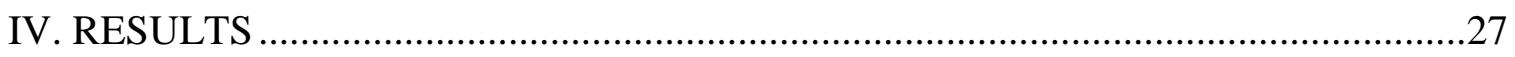

Summary Statistics: Field visits to Seed-take Patches by Sex ..................................27

Summary Statistics: Visits, take and handling at Seed-take patches

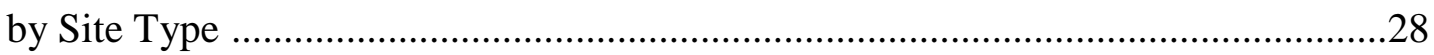

Summary Statistics: Seed Take in the Field ..........................................................29

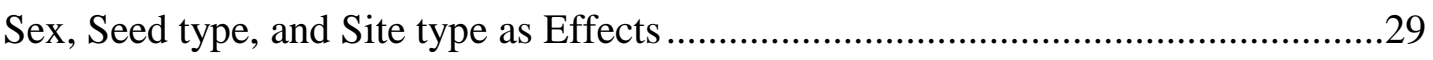

Post hoc tests of Sex Effects and Seed type selection ..................................................30

Giving up Density (GUD) differences for Veldt versus Native seed ...........................31

Differences between first and second sequential visits to a seed-take

patch within one night ........................................................................................

Seed Consumption and Captivity Trials.....................................................................

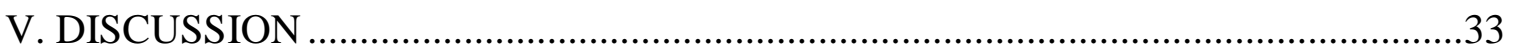

Kangaroo rats take Veldt grass under both field and controlled laboratory

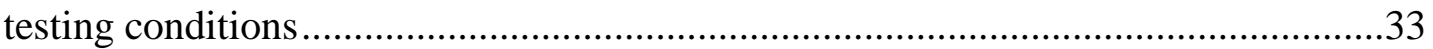

Kangaroo rats take the seed placed in the field and also off of naturally

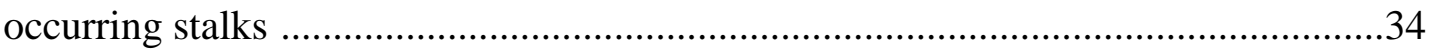

Evidence of Graminivory, but also Invasive Plant Use..............................................35

Implications of Negative density-dependent predation .................................................37

Kangaroo rats as keystone species .........................................................................

Females are taking more Veldt grass seed than males - function of

breeding season?

There was no shift in behavior between the $1^{\text {st }}$ and $2^{\text {nd }}$ sequential visits

to a seed-take patch within the same night ..............................................................42

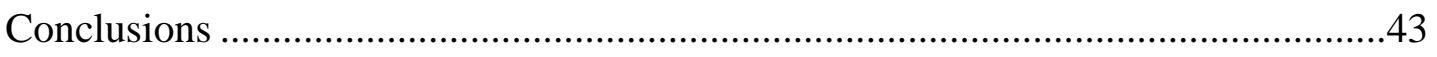

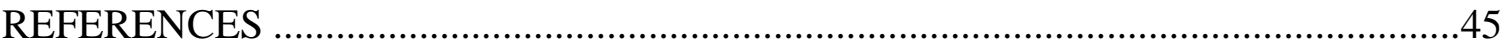

APPENDICES

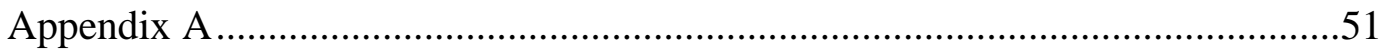




\section{LIST OF TABLES}

Table

1. Summary of the kangaroo rats marked and later detected across study sites.

Site names with "+” indicate Veldt grass presence, and site names with "_"

indicate veldt grass absence.

2. Experimental design for seed-take trials including, locations, whether seed-take patches were in an area with $(\mathrm{V}+)$ or without (V-) Veldt grass, seed-take trial dates, the average percent of the moon that was illuminated (percent visible), the number of kangaroo rats detected during each field trial, and the minimum spacing between seed-take patches (Y-maze with camera trap) placed in the field at the same time

3. Individual data for kangaroo rats used in laboratory seed choice/seed use trials

4. Summary table of the number of kangaroo rats that visited seed-take patches in the field, the average number of visits and average number of visits involving take as a function of sex and site-type.

5. Summary table of the number of kangaroo rats that visited seed-take patches in the field by site type, with total number of visits, number of visits with handling time and total number of visits with take shown.

6. The number (percentage) of kangaroo rat individuals that took seed from seed-take patches

7. Artificial seed-take patches were placed in the field to test if D.h. arenae would take Veldt grass (Ehrharta calycina)

8. For kangaroo rats with two sequential visits to the same seed-take patch in the same night, a Wilcoxon Signed Rank test was performed to examine whether there was a difference between the first and second experience 
for handling time, collecting time, or percent of available seed collected

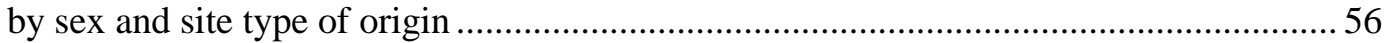




\section{LIST OF FIGURES}

Figure

Page

1. Example study sites with of Veldt invading coastal scrub

(left, ODSVRAV+) and non-invaded coastal scrub (right, ODSVRAV-)

2. Location of field sites use for seed-take trials. The dune complex is composed of contiguous dune system comprised of the Pismo, Oceano, Nipomo, and Guadalupe dunes

3. Map showing the three study sites in Black Lake Canyon

(Land Conservancy of San Luis Obispo)

4. Map showing the two Oceano Dunes State Vehicular Recreation Area (ODSVRA) study sites: ODSVRA Non-Veldt (ODSVRAV-) and ODSVRA Veldt (ODSVRAV+) 60

5. Seed-take patches consisted of paired seed-take boxes, with $1 \mathrm{~g}$ of seed (Veldt grass or Native seed cocktail) assigned randomly, each night, to each side, separated by 5 meters and monitored with an overhead game camera for 5 consecutive nights....

6. Diagram of home cage in which seed take trials took place. 61 


\section{Introduction}

There are few documented examples of native species using non-native plants as resources, but the documentations that do exist have begun shifting the paradigm from viewing these plants solely as "invasive" to recognizing them as "non-native" plants that could be exploited as a resource (Fimbel and Linders 2012, Theimer et al. 2012, \& Brusati and Johnson, 2012). When we think of invasives, it is easy to focus on one kind of ecological interaction - competition - as the non-native species comes to occupy niche space in the biological community that it invaded, and in the process may have reduced populations of native species or displaced native species from that community entirely. In plants, such competitive exclusion can alter the composition and structure of areas being invaded, creating novel habitats such as monocultures of the invader (Johnson and De León 2015).

Competitive interactions have been a primary focus of prior experimental research, but is there something about invasives that restricts them to purely competitive interactions within the new ecosystems? Or is it possible that additional types of ecological interactions, which may facilitate or retard invasion success or influence the dynamics of competitive interactions between invasive and native species, exist? Trophic interactions are one category of interaction that is likely to influence invasion success directly - and the dynamics of competitive interactions indirectly - because trophic interactions have the potential to reduce population size and shift reproductive or behavioral patterns in invading species (Johnson and De León, 2015). Take for example the case of apparent competition where one prey species has an indirect negative effect on another prey species because one or both prey species positively affects the predator 
species (Holt, 1977 and Veech, 2001). The positive effect on the predator can be an increase in the number of predators, an increase in the capture and consumption rate of prey, or predators aggregating at a patch of prey, which would have an indirect negative effect on both prey species (Veech, 2001). If the invader is a seed plant, the abundance of granivores might increase as a result of the plant introduction, which could cause increased seed predation overall and therefore a decline in the seed supply of multiple plant species (Dangremond et al., 2010). If seed predation rates are not uniform, meaning that some seed preference exists, then an invasive plant could have indirect negative effects on the native plant(s) with the most preferred seeds. Recent evidence suggests that consumer-mediated apparent competition poses a strong threat to native plants because the introduction of invasive plants can allow for large increases in consumer densities and consumption (Dangremond et al., 2010). In a study of coastal dune grasslands of northern California, the introduction of the exotic grass Ammophila arenaria (European beachgrass), introduced for dune stabilization, led to increased densities of Peromyscus maniculatus, which used the beachgrass as refuge. The increase in rodent densities increased consumption rates on native vegetation, where native vegetation occurred near beachgrass. So, this type of interaction is not only an interesting type of trophic cascade, but it is also a predator/prey (granivore/grain) interaction. Therefore, though there is general interest in and recognition of the negative effects that non-natives plants have on native vertebrates (e.g., Didham et al., 2006 and Zavaleta et al., 2001), it is crucial to explore positive trophic interactions and their potential indirect effects.

In experimental studies, granivores (seed consumers) and graminivores (grassseed consumers) have been demonstrated to affect plant community structure in desert 
habitats (Brown and Heske, 1990) and plant abundance in coastal dune habitat (Kauffman and Maron, 2006, Dangremond et al., 2010). In a study examining the effect of post-dispersal seed predation on two perennial forbs in a grassland, granivores such as Peromyscus maniculatus, were found to be the primary driver for differences in plant abundance in and out of small mammal exclosures (Bricker et al., 2010). The granivores were able to lower the plant abundance outside of the small mammal exclosures in this grassland habitat, which adds to similar work in desert and coastal dunes systems (Bricker et al., 2010). Native granivores can have important impacts on plant communities by suppressing seedling recruitment, which may influence the invasion success of exotics, whereby granivores target certain exotics but not others (Pearson et al., 2011). This is supported by the hypothesis of biotic resistance which states that invading species may experience varying degrees of resistance from biotic interactions such as predation, parasitism, and competition which can negatively affect the invaders success at becoming established and reproducing (Pearson et al., 2014). Granivory/graminivory of exotics can have long-term and widespread reductions of exotic plant populations which may result in community-level effects, such as conversion to exotic grasslands in the absence of granivorous/graminivorous rodents (Pearson et al., 2014, Brown and Heske, 1990). In a study in the Caldenal savannas of central Argentina native rodents represented an important source of biotic resistance to exotic plants by selectively predating on certain exotics. During this study, native rodents strongly suppressed the recruitment of several exotic plants enough so to affect densities of mature and flowering plants (Pearson et al., 2014). Biotic filters created by native granivores can help explain the variation seen in the success of invader species (Pearson et al., 2011, 
2014), but the current knowledge on how generalist consumers, such as granivores, contribute to biotic resistance is limited (Pearson et al., 2011).

In this study I focus on Veldt grass (Ehrharta calycina), a South African perennial grass species that was introduced to California, USA, in 1929 for cattle grazing and erosion control by ranchers and private landowners (Love 1948, cited in Pickart 2000). Veldt grass readily invades coastal dune habitat, moving in to open or disturbed areas. Once established, Veldt grass prevents or inhibits germination of native shrubs in the coastal dune scrub habitat (U.S. Air Force, 1996). The introduction of Veldt grass has been inferred to have detrimental impacts on native rodents in coastal California. It has been posited that Veldt grass has a detrimental impact on the habitat of an endangered species (Dipodomys heermanni morroensis) by converting the plant community from a shrubland to a grassland and thus converting suitable to unsuitable habitat (USFWS, 1999). Yet, the suggestion that Veldt grass creates unsuitable habitat ignores the potential for even simple trophic interactions. This is inconsistent with the fact that Veldt grass could be used as a seed resource because it was introduced into the geographic range of a native graminivore (Dipodomys heermanni). Trophic interactions might indeed be the expectation (Bricker et al., 2010, Dangremond et al., 2010, \& Pearson et al., 2011, 2014). Therefore, herein, I consider the potential for positive trophic interactions between a graminivore and an introduced non-native grass. If there are trophic interactions, then apparent competition would also need to be considered.

Dipodomys heermanni is one of nineteen species of kangaroo rats in the genus Dipodomys (Order: Rodentia, Family: Heteromyidae) (Kelt, 1988). All Dipodomys have large hind legs, relatively short front legs, a long tail, large head, and external cheek 
pouches used for transporting seed. Members of this genus are restricted to the warmer and often more arid portions of North America (Grinnell, 1922). Kangaroo rats in general are most diverse and most abundant when the habitat structure includes open spaces between the vegetation (Wood, 1935, Schmidt-Nielsen, 1964 \& Mares, 1993). Sympatric rodents generally forage under or near cover and therefore exposed seed patches have lower seed predation rates, unless they are exploited by kangaroo rats. Kangaroo rats are thought to have evolved to exploit these habitats in part through evolution of saltatorial bipedal locomotion as a response to the increased predation risk in the open (Bartholomew and Caswell, 1951 and Longland and Price, 1991). Bipedal locomotion, in conjunction with acute auditory capabilities (Webster 1962), makes kangaroo rats highly efficient at exploiting resources away from cover while also evading predators. Thus, kangaroo rats experience reduced seed competition in more open habitats.

The introduction of invasive plant species, including Veldt grass, generally causes infill of the open space within a plant community (U.S. Air Force, 1996). This reduction of open space is the characteristic habitat structure modification that Veldt grass has on early seral stages of coastal dune scrub communities. Veldt grass grows in clusters so dense that it eliminates the characteristic open sandy soils exploited by kangaroo rats (Kelt, 1988). Veldt grass can apparently out-compete the native shrubs (U.S. Air Force, 1996) and in extreme cases, can create a dense and continuous monoculture stand of vegetation (Figure 1). Veldt grass is becoming the dominant plant in the coastal dune scrub community on the California central coast and has changed the vegetative composition of these coastal communities (Kelt, 1988). 
The impacts of these vegetative changes for other species in these coastal biological communities are likely not limited to other plants, and it has been suggested that many taxa have declined in part due to the habitat modifications caused by Veldt grass establishment. The Morro Bay kangaroo rat (Dipodomys heermanni morroensis), for instance, was listed as a federally endangered species in 1970 and was recognized as an endangered species in 1971 by the state of California (United States Fish and Wildlife Service, 1999). The Morro Bay kangaroo rat is one of the nine subspecies in the species Dipodomys heermanni (Kelt, 1988). The decline of D.h. morroensis populations is attributed to several possible causes, (reviewed by Kofron and Villablanca, submitted) including habitat destruction due to residential, agricultural, and commercial development, predation by domestic animals including cats and dogs, burrow destruction by pedestrians and vehicles, competition with other mammals, the reduction of a large population into smaller fragmented populations, and alterations to the native plant communities through succession and the introduction of invasive species (USFWS, 1999; reviewed by Kofron and Villablanca, submitted). Though Veldt grass is considered to be only one of several ecological changes that led to the decline of $D$. h. morroensis and other kangaroo rat species because of Veldt grass's structural modifications to the habitat, its presence is considered in a somewhat dogmatic fashion. Habitat areas with Veldt grass are simply regarded as unsuitable for Dipodomys heermanni (USFWS, 1999, USFWS 2011; Kofron and Villablanca submitted) because evidence suggests that the optimal plant community for $D$. heermanni (and D. h. morroensis in particular) is the early seral stage of a coastal scrub or maritime chaparral community (Stewart and Roest 1960, Kofron and Villablanca submitted). Small shrubs that are widely spaced 
characterize the early seral stages of these plant communities. Succession from native dune scrub communities (early seral stage) to chaparral or densely vegetated communities (late seral stage) has historically been associated with a transition from suitable to unsuitable habitat for kangaroo rats (Stewart and Roest 1960, Congdon and Roest, 1975, Kofron and Villablanca submitted). Therefore, Veldt grass is typically regarded as being detrimental to kangaroo rats.

The population declines of Morro Bay kangaroo rats could therefore have resulted from a decrease in suitable habitat through the introduction of Veldt grass (Kelt, 1988), or through a loss of early successional habitat as the plant community matured (USFWS, 2011, Kofron and Villablanca submitted). In either case, the role of Veldt grass is generally a foregone conclusion: areas of veldt grass habitat are simply regarded as unsuitable (USFWS, 1999, 2011). Yet this conclusion or inference has never been tested. This is, in part, due to the lack of study sites and study subjects. Although there is no current estimate of the size of the remaining $D$. h. morroensis population, it is believed that fewer than 50 D. h. morroensis individuals exist based on the last comprehensive population census, which was concluded in 1986 (USFWS, 1999). No individuals of this taxon have been seen in the wild since 1986 despite repeated efforts (Kofron and Villablanca submitted). The reduction in habitat, lack of specimens, and the possibility of extinction has made it increasingly difficult for scientists to study D. h. morroensis, so a surrogate study species has been identified. The surrogate will allow us to infer whether Veldt was potentially a cause of the decline of this endangered species. In addition, the surrogate will also allow us to explore the potential for trophic interactions between Veldt and kangaroo rats in general. 
Villablanca (2007) concluded that the Lompoc kangaroo rat (Dipodomys heermanni arenae) is the closest geographic and genetic relative to the Morro Bay kangaroo rat and is therefore the most suitable taxon as a surrogate for research. I identified sites occupied by $D$. h. arenae, which are similar in plant species composition and physiognomy to sites previously occupied by the Morro Bay kangaroo rat. Specifically, the native and surrogate study sites are characterized by open sandy soils, and early seral stages of the mock heather / silver beach lupine plant alliance of the coastal dune scrub plant community. Therefore, I posit that I identify a surrogate subspecies and surrogate study sites for studying the possible interactions between the endangered Morro Bay kangaroo rat and Veldt grass. Although this research might seem to be focused on a surrogate subspecies and habitat in order to understand possible mechanisms behind the decline of the Morro Bay kangaroo rat, that is not our only intent. This is simply a system where we can study the interactions between a native vertebrate/graminivore and a non-native plant, while simultaneously using a system with conservation relevance.

Previous research on the Lompoc kangaroo rat focused on gaining insight into Morro Bay kangaroo rats' food and habitat preferences (Stewart and Roest, 1960 and Congdon and Roest, 1975), breeding behavior and captive breeding programs (Roest, 1991), reintroductions of captive kangaroo rats into the wild (Gambs, 1986), and competitors (Gambs, 1986, reviewed in Kofron and Villablanca submitted). This research was aimed at attempting to restore the population size of $D$. h. morroensis and understanding the causes of decline of the D. h. morroensis population (USFWS, 1999, Kofron and Villablanca submitted). Although (captive) Heermann's kangaroo rats have 
been reported to eat the leaves and stems of grasses, but never the seeds (Stewart and Roest 1960), no study considers invasive species directly, nor Veldt grass specifically, in the context of kangaroo rat diet. Therefore, previous work (summarized in USFWS, 2011) suggest that Veldt habitats are unsuitable for kangaroo rats, but there is no empirical basis for determining how these kangaroo rats interact with Veldt grass, including whether seed from Veldt grass could be a food resource under some circumstances. This contrasts with the considerable evidence (discussed below) that kangaroo rats are grass seed predators and therefore could have trophic interactions with Veldt grass.

Brown and Heske (1990) suggest that kangaroo rats (D. spectabilis, D. merriami and $D$. ordii) take and consume grass seed, as evidenced in a 12-year study in the Chihuahuan Desert. The foraging of D. spectabilis, D. merriami, and D. ordii on these seeds had significant effects on local plant community structure, since test plots that excluded kangaroo rats showed a significant change from desert shrubland to grassland exhibiting at least a threefold increase in tall perennial and annual grasses along with an increase in arid grassland rodents (Brown and Heske, 1990). Kerley et al. (1997) tested for graminivory in kangaroo rats (D. ordii) both in the lab and in the field. In the field Kerley and coworkers (1997) also used exclosure plots to test for top down ecological effects of kangaroo rat graminivory. Three types of exclosure plots were used: plots excluding large kangaroo rats (excluding Dipodomys spectabilis) but allowing medium kangaroo rats to enter, plots excluding medium sized kangaroo rats (excluding Dipodomys merriami and D. ordii), and plots excluding rodents (excluding all rodents including kangaroo rats). Grass cuttings were virtually absent in the rodent and medium- 
sized kangaroo rat exclosures, whereas in the control and large kangaroo rat exclosures grass cuttings were evident. This suggests that the medium-sized kangaroo rats ( $D$. merriami and $D$. ordii) were responsible for the grass cutting under field conditions. In the lab, Ord's kangaroo rats (Dipodomys ordii) were provided with three different species of grass, for 1-4 days and consumption of the plant was monitored. The kangaroo rats clearly cut off and consumed tillers from all three species of desert grasses. The kangaroo rats consumed a large percentage of the grasses presented; suggesting that graminivory by kangaroo rats can impact desert grasslands (Kerley et al. 1997).

In this study, I examined whether Veldt grass seed may be a food resource for $D$. h. arenae in two ways: 1) first I tested whether $D$. h. arenae collect Veldt seed when presented with artificial sources of Veldt seed in combination with native seed in the field, and 2) second, I examined whether Veldt seed is consumed by $D$. h. arenae using a captive exposure test in the laboratory. Because, other species of kangaroo rats are known to consume grass seeds (Williams and Kilburn, 1991) and have been shown to consume invasive grasses and other invasive plants (Brown and Heske 1990 and Longland, 2007), I predicted that $D$. h. arenae would take and consume Veldt grass seed in both of these scenarios. In addition, I predicted that D. h arenae individuals that co-occur with Veldt grass in the wild would collect more Veldt grass seed than the individuals for whom Veldt seed is a novel resource. I tested for this experience effect by deploying artificial sources of Veldt and native seeds in habitats dominated by either Veldt grass or native plants, and then tested for differences in seed preference for kangaroo rats in those habitat types. Habitat use and foraging preferences in rodents, including kangaroo rats, is measured using the proxy giving up density (GUD). GUD is defined as the amount of 
seed remaining in a patch after a forager leaves (Price and Correll, 2001). Under a specific set of assumptions, models suggest that the GUD provides quantitative information on fitness costs and benefits of foraging, on the ability of foragers to assess patch quality, and on diet selection (Price and Correll, 2001). An animal should "give up" foraging when the benefits of continuing to forage are outweighed by the costs of searching, handling time and digestion, missed opportunity costs, and predation risk. GUDs are generally compared among differing seed patches and a lower GUD indicates a lower net cost at a patch (Carthey and Banks, 2015). Much of what is known about kangaroo rat foraging is based on assumptions of GUD and optimal foraging (Brown, 1988 and Price and Correll, 2001). The results will address GUD in order to articulate with the large body of knowledge that uses that metric. The data has significance for informing habitat management actions aimed at Veldt grass in kangaroo rat habitats, for understanding the decline of Morro Bay kangaroo rats (D. h. morroensis), and understanding how ecological trophic interactions might influence the dynamics of plant invasion more broadly. 


\section{Methods}

\section{Experiment 1: Observations of Veldt and native seed collection in the field}

\section{$\underline{\text { Study sites }}$}

Kangaroo rats (D. h. arenae) were studied in five locations located in the PismoOceano-Nipomo-Guadalupe Dunes Complex on the central coast of CA, USA, (Figure 2). Three of the study sites were located on Land Conservancy of San Luis Obispo property along Black Lake Canyon in Arroyo Grande, CA (Figure 3) and two were located in or adjacent to the Oceano Dunes State Vehicular Recreation Area (ODSVRA) in Oceano, CA (Figure 4). These field sites were chosen for their similarity in habitat types and similarity to the habitat of D. h. morroensis. They consisted of coastal dune scrub, or more specifically, the mock heather / silver beach lupine alliance of coastal dune scrub, including areas of open sandy soils. The sites differed based on the presence or absence of Veldt grass. Veldt grass was regarded as "present" if the home range of an individual kangaroo rat had more than $10 \%$ Veldt grass cover, as determined using a relevé method of estimating plant cover within $20 \mathrm{~m}$ of a trap station. Two field sites lacked Veldt grass (Black Lake [BLV-] and ODSVRA [ODSVRAV-]), and three field sites had Veldt grass (Callender [CV+], Black Lake [BLV+], and ODSVRA [ODSVRAV+]). Qualitatively, the sites with Veldt grass - ODSVRAV+, CV+, and BLV+ - had less open (sparsely vegetated) sandy soil compared to the non-Veldt sites as would be expected because Veldt grass fills in open spaces between vegetation. 


\section{Study Animals: Live trapping and individual marks}

Adult kangaroo rats were collected at each study site (Figure 2) between 7 February and 8 March 2014 using Sherman Extra Long Live Traps baited with rolled oats. Traps were set along trap lines and grids that were georeferenced so that capture locations could be re-located for use in seed-take trials. At each site, traps were set at dusk for three consecutive nights or until no new individuals were captured (maximum of 7 nights at Callender $\mathrm{V}+$ site). This saturation trapping was conducted in an attempt to collect all individuals in the local habitat area of each site, since it was important to capture and mark kangaroo rats so that each individual could be identified in the wildlife camera images (see below). All kangaroo rats collected were individually marked with a uniquely numbered ear tag and hair clip on the dorsum in a unique pattern. This unique dorsal hair clip allowed for the identification of individual kangaroo rats foraging at a seed-take station monitored with a game camera. Each individual also had its sex determined, before being released at the site of capture. .

Field marks were tested in a pilot project. One method of marking, hair dye on the tail and rump, was tested on 10 individuals. This method was rejected because the marks were hard to discern on the game cameras (mock seed-take station) and faded after 4-7 days. A second method, hair-clipping on the dorsum, was tested on twenty-seven individuals. This method was selected because marks were visible in game cameras and marks persisted for more than two months. 


\section{$\underline{\text { Seed box for foraging (seed-take) trials }}$}

Y-maze seed boxes (Figure 5, hereafter referred to as "seed-take patches") and camera traps (using game cameras) were used to record whether Lompoc kangaroo rats from the Pismo-Oceano-Nipomo-Guadalupe Dunes Complex collect Veldt grass seed in the field, and habitat experience of an animal (e.g., Veldt grass dominated, or native plant dominated) influences seed collection behavior. The seed boxes were constructed of aviary wire mesh, lacked a lid and a floor, but had 4 sides ( 78.74 by $25.4 \mathrm{~cm}$ and 48.26 by $25.4 \mathrm{~cm})$. The front of the seed box had an opening $(7.6 \mathrm{by} 8.9 \mathrm{~cm})$ that allowed small mammals to enter the box. A divider (Figure 5), also made of aviary wire, projected from the center of the back wall and divided the box into two halves. This divider ended opposite the entrance and resulted in an entrance area $(8.9 \mathrm{~cm}$ tall, $7.6 \mathrm{~cm}$ wide and 7.6 $\mathrm{cm}$ deep) that forced the animals to enter one of the two sides of the box. The design of the Y-maze allowed for paired and simultaneous exposure to two seed options (see below).

A total of 28 paired seed-take patches (two patches per pair, Figure 5) were monitored during field seed collection trials. One seed-take patch in the pair was placed at the location where an individual had previously been trapped. The second seed-take patch was placed in one of the four cardinal directions (chosen randomly) and five meters away from the first seed box (Figure 5). When possible the paired patches $(\mathrm{N}=18)$ were placed where only a single individual was known to occur. If individuals were known to occur within 0-2 stations of each other, then all of those stations $(\mathrm{N}=10)$ and individuals were monitored at the same time in order to provide all individuals in a cluster with a seed box at the same time.. During these simultaneous trials, the seed-take patches were 
placed at capture locations of one individual and then as far as possible from that one, and still within the known capture localities of the other individual. Therefore, a total of 28 pairs of seed-take patches were placed in the field (each monitored for five consecutive nights) for a total five-week monitoring period. The 28 pairs allowed targeting of 14 non-Veldt animals (from a habitat area that lacked Veldt grass) and 14 Veldt animals (from a habitat area with Veldt present).

$\underline{\text { Seed }}$

Veldt grass was collected from Los Osos, CA, and from the Callender Veldt site in Arroyo Grande, CA. The former site is within the geographic range of D.h. morroensis and the latter of D.h. arenae. Veldt grass seed was collected by stripping the seed head off of the stalks. The seed was then autoclaved to prevent germination and allowed to dry before being used in trials. One gram of Veldt grass contains on average 58.5 Veldt grass seeds ( $n=20 \mathrm{~g}$ of Veldt grass seed sampled). In addition to Veldt grass seed, a native seed cocktail was obtained from S\&S Seeds, Carpinteria, CA, and was autoclaved to prevent germination in the field. The native seed was a coastal sage scrub mix including Artemisia californica, Camissonia cheiranthifolia, Collinsia heterophylla, Encelia californica, Eriogonum fasciculatum, Eriophyllum confertiflorum, Eschscholzia californica, Lasthenia californica, Lotus scoparius, Lupinus succulentus, Mimulus aurantiacus, Nassella pulchra, Salvia apiana, Salvia mellifera, Sisyrinchium bellum and Vulpia microstachys. Five of these 16 species are known to occur in the Pismo-OceanoNipomo-Guadalupe Dunes Complex. Of the 11 remaining species, four do not occur, but their genera do, and 7 are not known to occur. Therefore, nine of the 16 native seeds are represented by local species or congeners, and seven are not. Veldt grass seed and native 
seed cocktail were premeasured into individual 1 gram aliquots and transported to the field.

\section{Game cameras}

A motion-activated game camera (Bushnell Trophy Camera HD 119736C) was used at each seed-take patch to video record the behavior of kangaroo rats that visited the seed patch. The game cameras were fastened perpendicular to 5' fence posts and above the seed-take patch (Figure 5) such that both seed types and the entrance could be easily seen. The cameras were set to record 25 -second videos, once activated, with a reset delay period of 1 second. Each 25-second video clip is referred to as an "event." To reduce the brightness of the flash and thus allow for individual hair clip patterns to be clearly seen, electrical tape was used to cover all but the center two flash bulbs, when the flash was set on "High".

\section{Seed take in the field}

Seed-take patches were placed in the field to test the prediction that when presented with Veldt grass seed in the field, rats will take the seed (seed-take trials). Each night the seed-take patch (Figure 5) contained $1 \mathrm{~g}$ mass of Veldt grass seed on one side of the Y-maze and $1 \mathrm{~g}$ of a native seed cocktail on the other side (see above for seed sources). The side that contained Veldt grass was randomly assigned each night. Seedtake patches were set (baited with seed) every evening as close to sunset as possible. Each night, any seed remaining in a seed-take patch from a previous night was removed (via sand sifting) before being replaced by a new $1 \mathrm{~g}$ aliquot of seed for the current night's observations. After 5 nights, the boxes were moved to a new location and another 
5-night trial began. The five night trials continued for five consecutive weeks (Table 2) until each station $(n=28)$ was run for five nights. Seed-take patch trials were run from 13 April to 16 May, 2014, intentionally covering a full lunar cycle (Table 2).

\section{$\underline{\text { Data collected from videos }}$}

After each 24 hr. period each camera's memory card was brought into the lab and the videos from each night observed. For each seed-take patch, I recorded the following: animal ID, date, time of night, camera location, site type (Veldt or non-Veldt), type of seed handled, and type of seed collected. Behavioral data quantified from the videos included the following: amount of time the animal spent handling and collecting seed, an estimate of how much seed was taken (see below), and the sequential event number (per night and total) for each individual.

Individuals with repeated visits during the five-night trial were the primary focus of the analysis, and data on animals that did not repeatedly (at least twice) visit the seed patches were also recorded but not used in the primary analyses. For individual kangaroo rats that visited a seed-take patch at least twice, the amount of time spent handling and collecting each seed type (native and Veldt) per event was averaged over all events in the five night trial. The averaged time per event was calculated by dividing the cumulative amount of time spent handling or collecting (separately and combined) across all nights, divided by the total number of events for an individual, multiplied by 25 seconds (event duration). This value provided a measure of handling and collecting time for each individual irrespective of the number of visits (or events). 
I also estimated the amount of seed collected per visit (in cases when seed was actually collected). It was impossible to directly measure (e.g., weigh) the amount of seed collected because it was impossible to control all relevant field conditions. For example, diurnal birds started collecting seed at dawn, generally before we could have collected the remaining seed from the soil. Therefore, the only way to measure the amount of seed collected was to estimate the area of the seed patch collected from the images. The amount of starting seed was known $(1 \mathrm{~g})$. The amount of seed collected in the first visit could be estimated as the percent of the seed pile removed, measured in $10 \%$ increments. But after the first visit, the reference image of $1 \mathrm{~g}$ changed due to depletion, and potentially due to scattering. Therefore, the most accurate way to estimate the amount taken in subsequent visits was by comparing the seed pile immediately before foraging (patch size $_{\text {initial }}=$ remainder from previous visit) and immediately after foraging (patch size $_{\text {final }}=$ remainder after visit). The $\%$ of the patch taken per visit (PPT) for each of the subsequent visits following the first was calculated as follows for each visit, with the resulting value rounded to the nearest $10 \%$ increment:

$$
\mathrm{PPT}=\left(\text { patch } \text { size }_{\text {initial }}\right)-\left(\text { patch }_{\text {size }} \text { final }\right)
$$

This PPT value provided an estimate of the percent of seed previously remaining in a seed patch that was collected during each subsequent visit. The total amount of seed collected was then estimated from the cumulative (summed) PPT for each seed type (native vs. Veldt). This value for the total amount collected was then used to calculate an average $\%$ of the seed patch collected per visit value (APPT) by dividing the cumulative PPT by the total number of visits to a seed-take patch during which the same seed type was collected: 


$$
\mathrm{APPT}=\left(\sum \mathrm{PPT}\right) \cdot(\text { total } \# \text { of visits })^{-1}
$$

This APPT (average percent patch taken per visit) value was used to compare across conditions (for example Veldt seed vs. native seed), and was also used to compare the GUD of Veldt grass seed and native seed.

\section{Data analysis methods for video data}

\section{$\underline{\text { Summary Statistics }}$}

The number of individuals that took Veldt grass seed and native seed in the field along with the sex of the individual and site type were used to calculate the proportion of individuals that took Veldt grass seed and native seed by sex and site type. The APPT was also calculated.

\section{Effects of sex, seed type, site type or interactions - Repeated Measures ANOVA}

Square root transformation of average handling time, average collecting time, manipulation time, APPT per visit, and number of visits involving seed take values was conducted to achieve normality. Using a square root transformation on the 'number of visits involving take' resulted in an approach to normality (Shapiro-Wilk test of $\mathrm{p}<$ 0.0220, all other variables had a p-value $>0.05$ ). A Split Plot design was used as a method of performing a repeated measures ANOVA (rm ANOVA) in JMP (JMP®, Version 11.1, SAS Institute Inc., Cary, NC, 1989-2007. In this analysis, individual is a random effect and we control for the fact that the same individuals were sampled repeatedly, and sex, site type (Veldt vs. Non-Veldt habitat), and seed type (Veldt vs. Native) are fixed effects. I examined the relationships between site type and seed type and all of the following: the 
average handling time, average collecting time, APPT (see above) per visit, number of visits to a seed-take patch, and number of visits involving seed take at a seed-take patch. Significant differences were determined using an $\alpha<0.05$. The first rm ANOVA showed that average handling and average collecting time were not significantly influenced by sex, site type, seed type, or any interactions of the dependent variables. These two were therefore combined into an average manipulation time and then the same model was run for all of the dependent variables.

McNemar's tests were also conducted to examine frequency differences in manipulation time, APPT, number of visits, and number of take visits for Veldt and native seed. A McNemar's test was chosen as a more valid test than the rm ANOVA because it allowed for non-normal data with unequal variances, but it was not as powerful as the rm ANOVA and could not examine interactions. When the results of the rm ANOVA and McNemar's tests were compared there were no differences, so only the results of the rm ANOVA will be discussed further.

The cumulative percent of the patch taken is the reciprocal of GUD. GUD is defined as the amount of seed remaining in a patch after a forager leaves (Price and Correll, 2001). GUD has been used in a number of studies of kangaroo rats (Price and Correll, 2001, Brown, 1988, Valone and Brown, $1989 \&$ Bouskila, 1995) as a measure of seed and habitat preference, or of relative predation risk and energetic benefit and or missed opportunity costs. A seed patch that is foraged to a lower GUD is one that is exploited more fully. This is predicted to happen when the perceived reward compensates for the perceived risk and cost relative to a patch with less perceived reward or more perceived risk and cost. In the present context, if one seed type is foraged to a 
lower GUD, then that seed type is preferred or provides a greater reward for the risk and cost, though we are not testing for the mechanism behind the preference (e.g., moisture or nutritional content). We calculated the GUD of each foraging event $i$ for an individual as follows:

$$
\mathrm{GUD}_{\mathrm{i}}=1-(1 \cdot \mathrm{PPT})
$$

An average GUD per visit for an individual was calculated as:

$$
\Sigma \mathrm{GUD}_{\mathrm{i}} \text { (seed type) /\# of take visits }
$$

And, the nightly GUD was calculated for each individual as:

$$
\mathrm{GUD}_{\mathrm{ij}}=1-\left(\left(\left(1.0 * \mathrm{PPT}_{\mathrm{i}}\right)+\boldsymbol{\Sigma}\left(\left(1.0 * \mathrm{PPT}_{\mathrm{i}-1}\right) *\left(\mathrm{PPT}_{\mathrm{j}}\right)\right)\right)\right.
$$

I used an exponential transformation to more closely approximate normality. T-tests were performed to compare the GUD to the type of seed taken (Native or Veldt) for both average GUD for individuals and nightly GUD. Significant differences were determined using an $\alpha<0.05$. An ANOVA was not performed for these dependent variables because the site type sample sizes were too small for comparison, and therefore seed type by site type comparisons could not be made.

\section{Effects of prior experience on subsequent experience}

Wilcoxon Signed Rank tests were performed to determine if there were any differences between the first and second experiences for an individual at a seed-take patch. The first experience refers to an individuals' first visit to a seed-take patch, followed by its departure, and the second experience refers to the next sequential arrival at the same seed-take patch and on the same night as the first experience. This test was 
used instead of the parametric equivalent because the data were not normally distributed and could not be transformed to satisfy the assumption of normality. The tests examined the effects of sex and site of origin (Non-Veldt or Veldt habitat) on handling time, collecting time, and amount of seed collected. Sex was used as a grouping factor in this analysis because of the significant effect of sex on the amount of seed collected in the rm ANOVA (see below). Site Type was used as a grouping factor to examine whether individuals from different habitats of origin behave differently when first encountering these two seed types in a seed-take patch. Significant differences were determined using an $\alpha<0.05$. Sequential Bonferroni tests were applied for all cases where significance was detected (without correction). 


\section{Methods}

\section{Experiment 2: Controlled laboratory Veldt seed consumption test}

\section{$\underline{\text { Source population for captive seed consumption trials }}$}

Following the field trials, I performed seed consumption trials in the lab using captive animals, to determine if Lompoc kangaroo rats consume Veldt grass seed. Ten individuals were live trapped from the five study sites following completion of the field trials and transported to California Polytechnic State University, San Luis Obispo (Table 3). Five initially naïve individuals (from habitats without Veldt grass) and five experienced individuals (from habitats with Veldt grass) were randomly selected from all live trapped individuals. The non-Veldt group was made up of three males and two females and the Veldt group was made up of four males and one female. Efforts to equalize the numbers for each sex were unsuccessful (see trapping success below), in part because individuals used in the lab trials were only selected if they had not taken Veldt grass seed during the field trials.

\section{Housing Conditions}

Each animal was housed in an individual glass aquarium $(45 \times 25 \times 28 \mathrm{~cm})$ with a tight fitting plastic lid with a mesh panel $(8 \mathrm{x} 8 \mathrm{~cm})$ for ventilation. The cage floors were covered with at least $5 \mathrm{~cm}$ of sand (sensu Yoerg and Shier 1997, Shier and Yoerg 1999) that had been obtained from the site of capture. Nest jars, consisting of a 32-ounce glass mason jar inserted into a section of black PVC pipe, were provided in each aquarium. The mason jar was attached to a T-section of PVC pipe that acted as an entrance/exit (Yoerg 1999). Clean, compressed-cotton squares were provided for use as nesting 
material (Shier and Randall 2007). The sand in each aquarium, and nest jars, were cleaned after Thompson et al. (1995) and Shier and Randall (2007). Animals were given lettuce, as a source of free water, once a day throughout their time in captivity (methods follow Yoerg and Shier 1997, Shier and Yoerg 1999, Shier and Randall 2007, Thompson et al., 1995, Roest 1991). Lettuce was given as a source of free water (rather than free water itself) because these animals are adapted to very arid environments, and an excess of water is known to cause excessive urination, eventually leading to weight loss and weakness (Eisenberg 1967).

\section{$\underline{\text { Husbandry and lab maintenance cycles/schedules }}$}

For the first three days of captivity all individuals were given a standard diet of rolled oats and lettuce. After this acclimation period, three-day seed-take trials took place (see below). After the seed-take trials the animals were given the standard diet. This schedule applied to the first 7 animals brought into captivity. These individuals were maintained on the diet of rolled oats for approximately one month after trials before being switched to a new standard diet on July $3^{\text {rd }}, 2014$. The new standard diet consisted of a $1 / 4$ cup of equal parts rolled oats, wild bird seed mix and sunflower seeds along with lettuce. The diet of the captive animals was changed at this point as a form of enrichment for the kangaroo rats that had been in captivity for more than a month and to expose the individuals to different seed types that would later be used in trials. All animals, except for the last three individuals brought into captivity, were given approximately one month on the new diet before the second seed take trial was conducted. The last three animals brought into captivity (Table 3 ) were started on the new standard diet of a $1 / 4$ cup of equal parts rolled oats, wild bird seed mix and sunflower seeds along with lettuce. These three 
animals were given this diet for three days and then had a one-day seed take trial and were returned to their standard diet. The last three individuals were given 17 days between their first trial and second trial. Samples were separated into two sets because of the difficulty in obtaining (trapping) appropriate subjects from the field.

\section{Seed consumption trials in the lab}

Millet and sunflower seeds are known to be highly preferred by kangaroo rats (Price 1983, Lockard and Lockard 1971, Bowers 1990, Podolsky and Price 1980, Vander Wall 1998, Price and Longland 1989). Three types of seed were tested in these trials: husked millet, shelled sunflower, and Veldt grass. These seeds were chosen because of their size differences from Veldt and the ability to separate these seeds from the sand and from each other. Preference for these seeds ensured that kangaroo rats would consume some seed every night in the event they did not consume Veldt grass. Although this preference ensured some consumption of seed, it was unknown what the preference ranking would be for Veldt grass seed, because it has never been tested. Trials using the three seed types were conducted in each individual's home cage. During each night of a seed take trial individuals were given $1 \mathrm{~g}$ of each seed type, separated into piles, along with lettuce placed between the seed piles and the cage wall (Figure 6). Trials were run for three nights per animal. Placement of the three seed piles was consistent across all nights and individuals, but the exact location of each seed type relative to the others was randomly assigned every night (Figure 6). Seed was placed in the home cage of each individual between 1700 and 1800 every night. Before the start of the consumption trials, and between each of the three nights of trials, all sand and other contents of the cage and nest jar were removed; the sand was sifted of seed and seed fragments and replaced. 
Therefore, all seed that remained at the end of a night's consumption trial was removed by sifting, the seed was sorted by type, and weighed to determine how much seed of each type had been consumed in the preceding 24-hour period.

\section{$\underline{\text { Data Analysis }}$}

Seed consumption: day, seed type and interactions -Repeated Measures ANOVA

Amount of seed remaining was square root transformed to achieve normality. Sunflower seed consumption was not included in the analysis because all individuals consumed all sunflower seeds during every trial night. A Split Plot design was used in JMP as a method of performing a Repeated Measures ANOVA. In this analysis, individual is the random effect and we control for the fact that the same individuals were sampled repeatedly and seed type (Veldt vs. Native) and day are fixed effects. I examined the effect of seed type, day and the interaction of seed type and day on the amount of seed remaining after a 24 hour period. Significant differences were determined using an $\alpha$ $<0.05$. 


\section{Results}

Substantive trapping effort resulted in a low trapping success (approximately 3\% success rate). Two months of continuous trapping [approximately $2700+$ trap nights (trap night is one trap out for one night)] resulted in a trapping success that was significantly lower than normal [30-50\% success at capturing a kangaroo rat (pers. obs.)] for this plant community and trapping method. Population densities were particularly low in sites I designated as Veldt habitat. This study did not address the statistical significance of this apparent pattern. A consequence of the low abundance was that the statistical design was not always balanced across sex or habitat type categories (see below). Although 45 individuals were marked at the beginning of my study, across the five study sites, some locations had as few as three individuals while other sites had as many as 26 individuals (See Table 1). Beatley (1969) was the first to record a positive correlation between winter rains and desert rodent population size (and even presence/absence of reproduction). I believe the order of magnitude lower success rate of this study is attributable to the study being conducted during a 100-year drought in California, where the principle rains occur in the winter.

\section{Summary Statistics: Field visits to Seed-take Patches by Sex}

Nineteen Lompoc kangaroo rats, 9 males and 10 females, were captured at seedtake patches by game cameras during the five weeks of seed-take trials. The average per capita visits to a seed-take patch for females was 3.4 visits while the average per capita visits for males was 8.6 visits. Females averaged 1.7 visits (50\% of all visits) per capita that involved taking seed and males averaged 4 visits (46.5\% of all visits). Males and 
females are thus nearly identical in the proportion of visits that involved seed take, though males visited more often than females (Table 4).

\section{Summary Statistics: Visits, take and handling at Seed-take Patches by Site Type}

Of the 19 kangaroo rats, six individuals were from Veldt habitats (4 males and 2 females), and 13 were from non-Veldt habitats ( 5 males and 8 females) (Tables 4 and5). Visitation rates per individual were nearly identical across habitat types: kangaroo rats from Veldt habitats had an average of 5.66 visits per individual, to seed-take patches and non-Veldt kangaroo rats had an average of 6 visits per individual to seed-take patches (Table 5). In spite of the similarity in the average number of visits, animals from Veldt habitats had fewer visits (1.83 visits per individual) that involved seed handling or collecting time while animals from non-Veldt habitats had more visits (3.84 visits per individual) involving handling or collecting time. Such that, per capita, non-Veldt individuals handle seeds twice as often when they were at a seed-take patch. The number of visits involving seed take (Table 5) was more similar, with animals in Veldt habitats averaging 3 visits per individual taking seed and animals from non-Veldt habitat averaging 2.08 visits per individual involving seed take (Table 5). Therefore, individuals from Veldt habitats had a greater proportion of visits involving take than individuals from non-Veldt habitats, though individuals from Veldt habitat had fewer visits in which they handled/collected seed than individuals from non-Veldt. In other words, it appears that when Veldt animals handle, they are collecting a perceptible amount, whereas non-Veldt animals may handle but the amount collected can be imperceptible (more visits with handling that are scored as non-take visits). 


\section{Summary Statistics: Seed Take in the Field}

Twelve of the 19 kangaroo rats (63\%) were seen collecting native seed from the seed-take patches: $61.5 \%$ of the animals from non-Veldt habitats took native seed and $66.7 \%$ of the animals from Veldt habitats took native seed (Table 6). Nine of the 19 kangaroo rats (47\%) from the field trials took Veldt grass seed from a seed-take patch: $53.8 \%$ of the animals from non-Veldt habitats took Veldt grass seed and $33.3 \%$ of the animals from Veldt habitats took Veldt grass seed (Table 6). Three kangaroo rats (16\% or 2 from non-Veldt and 1 from Veldt habitats) that were captured by the game cameras at the seed-take patches did not take seed of any type.

One male from a Veldt habitat (ODSVRAV+) was recorded on the game camera collecting a Veldt grass seed head from the end of a stalk of Veldt grass. An additional male and one unmarked individual in a second area of Veldt habitat (Callender V+) were each seen collecting a Veldt grass seed head from the end of a Veldt grass stalk. These Veldt grass stalks were naturally occurring, and showed take that was not prompted by my experimental seed-take patches.

\section{$\underline{\text { Sex, Seed type, and Site type as Effects }}$}

There was no significant effect (at $\alpha<0.05$ ) of sex, seed type, or site type of origin for individuals with regard to average time handling (seconds handling out of all possible 25 second video events) and average time collecting (seconds collecting out of all possible 25 second video events) - therefore these two times were combined into a composite 'manipulation time' variable. Manipulation time was likewise not significantly influenced by sex, seed type, and site type of individual origin or any interactions (Table 
7). Therefore, even though it appears that when Veldt animals handle, they are generally collecting, whereas non-Veldt animals handle but are not always collecting (see above), they do not differ significantly in time spent manipulating or handling.

Sex was a significant factor in the average percent of the patch taken per visit (Table 7). Seed type, site type, sex by seed type interaction, and sex by site type by seed type interactions were not significant (Table 7). Sex was also a significant factor in determining the number of visits to a seed-take patch (Table 7), while site type, seed type and all interactions were found to have no effect (Table 7). The number of visits involving seed take was not significantly explained by sex, seed type, or site type of individual origin (Table 7). Males and females are thus nearly identical in the proportion of visits that involved seed take, though males visited more often than females.

\section{Post hoc tests of Sex Effects and Seed type Selection}

Results of the repeated measures ANOVA (above) indicate an effect of sex. I also found (Table 4) that males and females are nearly identical in the proportion of visits that involved seed take, though males visited more often than females. Therefore, several post hoc analyses were conducted to better determine the nature of these sex effects. A post hoc t-Test (equal variances) shows that females take a greater average percent of the patch (APPT) than males (one-tailed, t Ratio: $-1.914, \mathrm{df}=36, \mathrm{p}=0.0318$, with sequential Bonferroni correction). Females take a larger percent of the available seed pile (greater PPT) than males, while also spending less time foraging (fewer visits) than males. This is intriguing because males are visiting seed patches first (65\% of first visits) more often than are females (35\% of first visits). An additional post hoc t-test (unequal variances) shows that males have a greater number of visits to seed-take patches than females ( $t$ 
Ratio: $2.7809, \mathrm{df}=27, \mathrm{p}=0.0048$ ). Therefore, males visited the seed boxes more times, were more frequently the first to visit the patch, but took less seed than females, while not differing in the number of visits that involved seed take. One final post hoc t-Test (equal variances) shows that there is no significant difference between the average percent of the patch taken (APPT) for native seed and Veldt seed (one tailed, t Ratio: $-1.2249, \mathrm{df}=36, \mathrm{p}$ $=0.1143$, with sequential Bonferroni correction). Therefore, there is no evidence of Veldt seed avoidance, or native cocktail preference.

\section{Giving Up Density (GUD) differences for Veldt versus Native seed}

There was no difference between the average individual GUD for Veldt and native seed (two tailed, $\mathrm{t}=0.5629, \mathrm{df}=19, \mathrm{p}=0.5801$ ). There was also no difference in the nightly GUD for Veldt and native seed (two tailed, $\mathrm{t}=-0.06891$, $\mathrm{df}=19, \mathrm{p}=0.9455$ ). Therefore, we were unable to detect an effect of Veldt grass or native seed on GUD.

\section{Differences between first and second sequential visits to a seed-take patch within one} $\underline{\text { night }}$

Sex and site type did not affect the handling time, collecting time, or the percent of the seed pile taken between the first and second sequential visits by an individual within one night. (Table 8). Individuals were not behaving differently when the seed-take patch is a novel food source (first experience to seed-take patch) or once they have experienced a seed-take patch (second visit to a seed-take patch).

\section{$\underline{\text { Seed Consumption and Captivity Trials }}$}

All individuals ate all of the sunflower seed available in each of the nightly trials. The amount of seed remaining was significantly different between the seed types and 
days $(\mathrm{F}=2531.621$, $\mathrm{df}=45, \mathrm{p}<.0001$ and $\mathrm{F}=9.2795, \mathrm{df}=45, \mathrm{p}=.0004$, respectively $)$. There was also a significant interaction between seed type and day (F Ratio: 6.8184 , df $=$ $45, \mathrm{p}=0.0026$ ). A post-hoc $\mathrm{t}-\mathrm{Test}$ (unequal variances) showed that there was more Veldt remaining than Millet after a trial (one tailed, t Ratio: 37.42452, $\mathrm{p}<.0001$ ). Post hoc comparisons of Day relative to amount of seed remaining using the Tukey's HSD test indicated that the mean for Day $1(\mathrm{LSM}=0.554)$ was different from Days $2(\mathrm{LSM}=$ 0.4957) and $3(\mathrm{LSM}=0.4734)$, while Day 2 and 3 were not different from one another. 


\section{Discussion}

\section{Kangaroo rats take Veldt grass under both field and controlled laboratory testing}

\section{$\underline{\text { conditions }}$}

Kangaroo rats collected Veldt grass seed in the wild and in the lab, suggesting that Veldt grass invasion, rather than being detrimental to a keystone species in the coastal dune environment, may function as a seed source especially in areas of high Veldt grass invasion. The average percent of the patch taken (and time manipulating seed) was fairly constant across individual kangaroo rats, individual seed-take stations, and the first and second sequential times an individual kangaroo rat visited a station in one night. Differences in seed take from the field were not a function of seed type, but of other factors. Males visited seed-take patches more than females, but females had more visits to seed-take patches involving seed take than males. I do not attribute this to a difference in sample sizes of males and females since there were 9 males and 10 females. Instead, females seem to be more efficient at taking seed.

My study also involved examining whether experience with a Veldt grass habitat influenced foraging behavior. I observed differences in the proportion of time spent handling seed versus average amount of seed taken when comparing individuals from the two habitat types. Individuals from non-Veldt grass habitats showed a tendency to spend more time and take less seed than those from Veldt grass habitats, though this might just be due to individuals from non-Veldt grass habitat taking such a small amount that the take amount was below the limit of detection by the currently used methods. My data indicate that kangaroo rats collect Veldt grass seed under field conditions, and that there 
may be a sex difference in terms of how much, or how efficiently seed is collected. I was unable to find a difference in GUD for Veldt grass seed compared to a cocktail of native seed for seed-take trials in the field. This leads me to conclude that under these specific testing conditions, this species of kangaroo rat does not exhibit a preference for either seed type when collecting seed, when presented with both in the field. In addition, Lompoc kangaroo rats will consume Veldt grass seed when given Veldt grass in the lab along with sunflower seed and millet. Although kangaroo rats consumed Veldt grass seed in the lab, significantly less was consumed than highly preferred sunflower and millet (unfortunately, it was impossible to compare Veldt grass seed consumption to the consumption rate of a native seed cocktail). I conclude that $D$. h. arenae collect Veldt grass seed and consume it under some conditions.

\section{Kangaroo rats take the seed placed in the field and also off of naturally occurring stalks}

Strong support that Veldt grass acts as a seed source when native seed is also present was availed in videos that inadvertently captured three Lompoc kangaroo rats harvesting seed heads from naturally occurring Veldt grass stalks. Dipodomys heermanni will forage on grass seed heads by standing on their hind feet, holding the seed head with the forefeet, biting off the stem, and then filling their cheek pouches with the seeds (Tappe, 1941). Although other kangaroo rat species are known to exhibit graminivory (consumption of grass seeds) of invasive plants, this behavior has not been previously observed in $D$. h. arenae. I have now shown it in Dipodomys heermanni arenae with Veldt grass and under field conditions. Yet, the pervasiveness of this behavior must be highlighted: removing seed heads from other grasses has been documented in Dipodomys heermanni, Ord's kangaroo rats (Kerley et al., 1997), Giant kangaroo rats (Schiffman, 
1994) and Banner-tailed kangaroo rats (Schroder, 1979). Grass seeds were found to be the most important food item for Merriam's kangaroo rats in a study that looked at the cheek pouch contents of 411 individuals: grass seeds occurred in approximately $75 \%$ of the cheek pouches containing food (Bradley and Mauer, 1971).

Documenting the take of Veldt grass seed by kangaroo rats from naturally occurring seed stalks, and from the seed-take patches, when also presented with native seed, suggests that D.h. arenae, consider Veldt grass seed as an acceptable food source. It is likely an important food source in areas where Veldt grass has formed extensive stands or even monocultures. Veldt grass as a seed source supported by the observation that kangaroo rats can harvest naturally occurring panicles before they release seed. The tight panicle structure of Veldt grass may make it particularly susceptible to pre-seeddrop harvest.

\section{Evidence of Graminivory, but also Invasive Plant Use}

I not only documented that Lompoc kangaroo rats are taking grass seed, but that the grass seed they are taking is from an invasive plant. Heteromyids, which include kangaroo rats, have been shown to harvest seeds of introduced plants from the soil seed bank. Longland (2007) experimentally tested the impact of heteromyids on the seedling recruitment of Salsola paulsenii, an invasive weed in western Nevada. Longland found that heteromyids had a measurable effect on reducing the soil seed bank of S. paulsenii over a two-year period. Although seed predation by these heteromyids does not effectively control the invasive weed, it is likely that the weed would occur in much greater densities if these heteromyids did not prey on the seed (Longland, 2007). Likewise, Brown and Heske (1990) found kangaroo rats reduced densities of an invasive 
grass seed, Eragrostris lehmanniana, at a southern Arizona site. Seed predation by native rodents can likely reduce competitive effects of invasive plants on native plants (Longland, 2007; Brown and Heske, 1990). In this study system, seed predation by Lompoc kangaroo rats may have the same affects as those seen in the studies by Longland (2007) and Brown and Heske (1990), in which kangaroo rats may not be effectively controlling Veldt grass populations, but reducing the amount of Veldt grass that would be present without seed predation. Giant kangaroo rats (Dipodomys ingens) are dependent on exotic grasses, such as Bromus madritensis and Erodium cicutarium, which displaced native vegetation in the Carrizo Plain of California (Schiffman, 1994). The invasion of Veldt grass is displacing native vegetation in coastal dune scrub communities, much like the situation in the Carrizo Plain, reducing the amount of native seed available as a food resource. With a reduction in native seed resources, Lompoc kangaroo rats may also become dependent on an invasive grass seed as a food source. Likewise, $D$. heermanni is known to consume seeds from some species of grasses, even introduced species (Kelt, 1988). The Lompoc kangaroo rat is a medium sized kangaroo rat. The studies by Brown and Heske (1990) and Kerley et al. (1997) showed that medium sized kangaroo rats are graminivores. Therefore, given my specific results regarding Veldt grass collection and consumption, and a general potential for graminivory in medium sized kangaroo rats, it is predicted that Lompoc kangaroo rats utilize the seeds from the invasive Veldt grass to a degree roughly proportional to its abundance once Veldt grass becomes established. 


\section{Implications of Negative density-dependent predation}

I found a trend towards non-Veldt animals having more take visits of Veldt grass seed than Veldt animals. Evidence that more kangaroo rats from Veldt habitats have visits involving take of Veldt grass seed than kangaroo rats from non-Veldt habitats can be explained by negative density-dependent predation. Negative density-dependent predation is defined as seed predators having a preference for rare seeds (Young et al., 2013). In the case of kangaroo rats from non-Veldt habitats, Veldt grass seed is a novel food source or is very rare in areas where small clusters of Veldt grass border the habitat, so in the case of negative density-dependent predation, seed predators would target the rare Veldt grass seeds compared to the common native seed. For kangaroo rats from Veldt habitats the opposite would also be expected; Veldt grass can grow in dense monocultures often to the exclusion of native plants, subsequently making native seed less common.

Young et al. (2013) found that negative density-dependent predation on tropical trees by land crabs prevented non-dominant trees from encroaching on forests where another tree species was dominant, because of the high rates of seed and seedling predation on the rare tree species. As the study by Young et al. (2013) illustrates selective predation on rare seeds can promote large-scale diversity by protecting habitats from encroachment by outside or rare species. It is therefore possible that kangaroo rats living in non-Veldt habitats may be playing a role in maintaining Veldt-free habitats through negative density-dependent predation on rare Veldt seeds. Likewise, above some threshold, kangaroo rats may begin to facilitate monoculture stands of Veldt by consuming rare native seeds. Thus, considering only the plants, it would appear that 
Veldt is outcompeting the natives. This same form of apparent competition, in which it appears that a plant outcompetes another plant, but in which, in reality, seed predation drives the community structure rather than plant/plant competition, has been demonstrated in other desert granivore systems (Holt, 1977; Veech, 2001). Veech (2001) studied apparent competition in two heteromyid rodents (Merriam's kangaroo rats and little pocket mice) examining the effects of seed preference and density dependence on seed choice. Veech's study (2001) documented short-term competition among seeds due to seed predator behavior, but found that seed preference, density dependence and potentially other prey searching and prey capturing behaviors caused apparent competition. Understanding how such interactions influence the threshold, or tipping point, whereby invasive species become dominant in abundance might provide for currently unrecognized Veldt grass management options, or at least a better understanding of the trophic interactions in this system.

\section{Kangaroo rats as keystone species}

Graminivory by kangaroo rats has a significant impact on the persistence of viable grass seed and seed predation, by kangaroo rats, is known to structure plant communities and abundance (Brown and Heske, 1990; Longland, 2007). Graminivory provides a mechanism that appears to explain the correlative relationships observed between medium sized kangaroo abundance and plant community composition, wherein a high abundance of kangaroo rats can decrease abundance of grasses, while the conversion of shrubland to grassland occurs when kangaroo rats are excluded see Brown and Heske 1990. 
Understanding the foraging habits of kangaroo rats, including graminivory, may in part explain why, in the absence of kangaroo rats, a grass species can dramatically increase in abundance and change a shrub habitat into a grassland habitat (Kerley et al., 1997). If Lompoc kangaroo rats do utilize Veldt grass seed it would justify assessing their effect as "seed predators" and as a possible bio-control mechanism, especially when Veldt grass seed is rare. If graminivory by kangaroo rats helps to structure plant communities (Brown and Heske, 1990, Kerley et al. 1997), then it is possible that even fluctuations in the seed predator's population size could have consequences on the plant community structure or the propensity of Veldt to invade a particular patch. If there is apparent competition occurring, then kangaroo rats cannot be considered exclusively graminivores because they are taking seed from other plant types besides grasses (granivores). Heermann's kangaroo rat is documented to take seeds from multiple species of shrubs including Lotus scoparius, Ericameria ericoides, Lupinus chamissoni, Erodium cicutarium, Mimulus aurantiacus along with other grass species such as Bromus rubens, Avena fatua, and Festuca megalura (Kelt, 1988)..

Kangaroo rats are considered keystone species because of their disproportionately large control over the structure and function of the community relative to their abundance (Power et al., 1996). This was first demonstrated by Brown and Heske's (1990) wellknown exclusion study examining the effects of kangaroo rats in the Chihuahuan Desert which found that experimental exclusion of kangaroo rats shifted the Chihuahuan Desert plots from shrubland to grassland. Through seed consumption, soil disturbance, and mound building, kangaroo rats influence habitat patchiness across the landscape (Davidson and Lightfoot, 2006). In a study of a desertified grassland, Davidson and 
Lightfoot (2006) found that mounds of both banner-tailed kangaroo rats and black-tailed prairie dogs supported distinct combinations of plant species relative to the rest of the landscape, and where these species co-occurred, plant species richness andlandscape heterogeneity increased. Brock and Kelt (2004) examined the effects of the endangered Stephens' kangaroo rat (Dipodomys stephensi) on vegetative cover through the use of exclusion plots. After one year of exclusion of D. stephensi there was a decrease in plant species diversity and seed predation and an increase in herb cover and Erodium abundance. Foraging and soil disturbance (trail maintenance, dust-bathing, and burrowing) by $D$. stephensi correlate negatively with vegetative cover. This negative impact on the vegetation creates more bare ground, maintaining the sparsely vegetated, early seral stage habitat preferred/exploited by kangaroo rats (Brock and Kelt, 2004). Kangaroo rats negative impact on vegetation may explain why we have continued to observe kangaroo rats in areas of Veldt grass. Although it is believed that Veldt grass creates unsuitable habitat, because it eliminates open space (USFWS, 1999) Lompoc kangaroo rats living in habitats with invading Veldt may be countering the shift to unsuitable habitat. Kangaroo rats may be countering this shift through foraging, thus modifying the Veldt's community structure impacts, through soil disturbance, and directly by consuming Veldt grass seed. If we accept kangaroo rats as a keystone species, then we should predict that in areas with fewer kangaroo rats there is lower seed predation and less soil disturbance. In these areas there would be direct plant-plant competition as part of the invasion process. In contrast, in areas with more kangaroo rats there is greater seed predation and soil disturbance. In these cases, apparent competition might be a part of the invasion process. This view of invasion focuses on seed, but 
rhizomatous expansion of Veldt grass should also be considered as part of the invasion process (and is not considered here).

Females are taking more Veldt grass seed than males- function of breeding season?

Female $D$. h. arenae were found to take more seed than males during the field trials. This difference between the sexes may be explained by the seasonality of the field trials. Field trials took place at the beginning of the breeding season, which has been documented to correlate with increases in activity (Kenagy, 1973 and Behrends et al., 1986a). Females are more energy limited than males during the breeding season because they are responsible for gestation, lactation, and parental care. The energetic demands of pregnant or lactating females are high and foraging can provide immediate reproductive gains for these females which are more active during these times (Behrends et al., 1986a). For a female kangaroo rat the limiting resource is food, whereas for a breeding male the limiting resource is females in estrous (Shier and Randall, 2004).

Females as a limiting resource for males may be an alternative explanation for the pattern I observed. One can think of it as female $D$. h. arenae taking more seed than males during the field trials, or as males taking less seed than females. Males travel greater distances from the center of their home range during the breeding season reflecting increased attempts to access limiting females (Shier and Randall, 2004). Males that expand their home ranges increase their chances of becoming familiar with neighboring females. Females prefer to mate with familiar males (Randall, 1991). These long distance movements and focus on finding mates may decrease the amount of time that males spend foraging on any one patch. Indeed, it is quite plausible that both factors, 
male decrease in foraging with increase in movement and female increase in foraging, might lead to a sex effect in average percent of the patch taken per visit as detected here.

\section{There was no shift in behavior between the $1^{\text {st }}$ and $2^{\text {nd }}$ sequential visits to a seed-take} patch within the same night

I found no shift in behavior from first to second sequential visits at a seed-take patch within the same night. I had predicted that handling time would increase after the first experience because there should typically be less seed in the seed-take patch by the second visit which would lead to more time spent picking the seeds out from the sand. I predicted that the opposite would happen for collecting time because there would be fewer seeds to collect, meaning the time individuals spend collecting seeds at a patch would decrease. My results suggest that kangaroo rats will return to a profitable patch and sort for seeds even after the patch has become visibly depleted. Therefore, it is possible that prior experience is also critical for driving returns to food patches. Seven of the 19 individuals recorded at the seed-take patches returned to the same seed-take patches on the next consecutive night, whereas, the other 12 individuals may have returned on multiple nights though not on consecutive nights. Individuals returning to seed-take patches multiple times in one night and on consecutive nights suggests it is quite likely that foraging is not random, that season (eg., breeding season) and experience potentially influence foraging decisions. Recently Price and Correll (2001) have called into question some of the fundamental assumptions that subtend the use of GUD as a metric of preference and habitat use. Their focus was primarily on the lack of evidence for the GUD assumption of random foraging. Therefore, it would be critical to conduct research to determine if the GUD literature and its assumption of random foraging, is a 
solid basis for understanding foraging strategies. Both within- and between- night patterns suggest that foraging is non-random with respect to encountering patches and that prior experience drives the decision to return to a patch. Our results show that even when males are aware of a seed patch, they take less seed, meaning that males have a higher GUD at a seed-take patch than females. We ascribe this effect to mating season correlates: males explore and use larger areas (in order to access more females), and females exploit seed resources that they encounter to a greater degree (ostensibly to procure more energy and nutrition for reproduction efforts). This means that males and females may not forage randomly at all during the breeding season. This would call experiments using GUD as a proxy for foraging decisions, into question if they were conducted during the breeding season.

\section{$\underline{\text { Conclusions }}$}

When compared to two highly preferred seeds (sunflower and millet), Veldt grass seed was still consumed, albeit in smaller quantities. Heteromyids have been observed to switch their diets from a less-preferred seed to a pure diet of highly preferred seed when the preferred seed becomes more abundant (McAdoo et al., 1983). This was evidenced in our lab trials in which kangaroo rats consumed all of the sunflower seed every time, most of the millet, and some Veldt grass seed, but in much smaller quantities when compared to consumption of the two highly preferred seeds (Price 1983, Lockard and Lockard 1971, Bowers 1990, Podolsky and Price 1980, Vander Wall 1998, Price and Longland 1989). The diets of kangaroo rats have been shown to shift depending on availability of seeds in relation to production and seasonality (Brown et al., 1979, Reichman, 1975, \& Reichman and Van De Graaff, 1973). Kangaroo rats whose home ranges are located in 
extensive stands of Veldt grass have little/no options in terms of seed choice; there may be very few native plants present and these native plants may not be within the home range of an individual. In these circumstances, my lab results support the idea that kangaroo rats consume Veldt grass seed even though the use of such non-native seed as a food may be reduced when another, more preferred, seed source becomes available. Diet switching by kangaroo rats may be a cause of short-term apparent competition among plants (Veech, 2001). Kangaroo rats are known to forage for highly preferred seeds and switch to the less preferred seed types when they have depleted the more preferred seeds (Veech, 2001). This dietswitching allows the kangaroo rats to continue foraging in an area that contains both seed types instead of incurring a cost of travelling to another seed patch (Veech, 2001).

My results not only have implications regarding the (unknown) relative habitat quality of home ranges that are dominated by Veldt grass, but also for the possibility that apparent competition is important given the trophic interactions and differential seed utilization I have demonstrated here. 


\section{REFERENCES}

Bartholomew, G.A. Jr., and H.H. Caswell Jr. 1951. Locomotion in kangaroo rats and its adaptive significance. Journal of Mammalogy 32: 155-169.

Beatley, J. C. 1969. Dependence of desert rodents on winter annuals and precipitation. Ecology, 721-724.

Behrends, P., M.Daly, and M.I. Wilson. 1986. Aboveground activity of Merriam's kangaroo rats (Dipodomys merriami) in relation to sex and reproduction. Behaviour 96: 210-226.

Bouskila, A. 1995. Interactions between predation risk and competition: A field study of kangaroo rats and snakes. Ecology 76: 165-178.

Bowers, M.A. 1982. Foraging behavior of heteromyid rodents: Field evidence of resource partitioning. Journal of Mammalogy 63: 361-367.

Bradley, W.G. and R.A. Mauer. 1971. Reproduction and food habits of Merriam's kangaroo rat, Dipodomys merriami. Journal of Mammalogy 52: 497-507.

Bricker, M., D. Pearson, and J. Maron. 2010. Small-mammal seed predation limits the recruitment and abundance of two perennial grassland forbs. Ecology 91: 85-92.

Brock, R.E. and D.A. Kelt. 2004. Keystone effects of the endangered Stephens' kangaroo rat (Dipodomys stephensi). Biological Conservation 116: 131-139.

Brown, J.H., E.J. Heske. 1990. Control of a desert-grassland transition by a keystone rodent guild. Science. 250 (4988):1705-1707.

Brown, J.H., O.J. Reichman, D.W. Davidson. 1979. Granivory in desert ecosystems. Annual Review of Ecology and Systematics 10: 201-227.

Brown, J.S. 1988. Patch use and an indicator of habitat preference, predation risk, and competition. Behavioral Ecology and Sociobiology 22: 37-47.

Brusati, E. and D. Johnson. 2012, "A survey of land managers using non-native plants in restoration", Bridging the Gap: Connecting People, Nature, and Climate. North America Congress for Conservation Biology. Oakland, CA, Oakland Convention Center.

Carthey, A.J.R. and P.B. Banks. 2015. Foraging in groups affects giving-up densities: solo foragers quit sooner. Oecologia DOI 10. 1007/s00442-015-3274-X

Congdon, J. and A. Roest. 1975. Status of the endangered Morro Bay kangaroo rat. Journal of Mammalogy 56:679-683. 
Dangremond, E.M., E.A. Pardini and T.M. Knight. Apparent competition with an invasive plant hastens the extinction of an endangered lupine. Ecology 91: 22612271.

Davidson, A.D., and D.C. Lightfoot. 2006. Keystone rodent interactions: prairie dogs and kangaroo rats structure the biotic composition of a desertified grassland. Ecography 29: 755-765.

Didham, R.K., J.M. Tylianakis, M.A. Hutchison, R.M. Ewers and N.J. Gemmell. 2005. Are invasive species the drivers of ecological change? TRENDS in Ecology and Evolution 20: 470-474.

Eisenberg, J.F. 1967. Handbook on the care and management of laboratory animals, $3^{\text {rd }}$ ed. Baltimore, Williams and Williams.

Fimbel, C and M. Linders. 2012, “Anathema! Planting non-native species for butterfly recovery on Washington prairies", Bridging the Gap: Connecting People, Nature, and Climate. North America Congress for Conservation Biology. Oakland, CA, Oakland Convention Center.

Gambs, R. D. 1986f. Introduction of captive Lompoc kangaroo rats (Dipodomys heermanni arenae) into a protective enclosure on a native habitat at "Dune Lakes" (San Luis Obispo County), California. Final Report, California Department of Fish and Game, Sacramento, CA. 41 pp.

Grinnell, J. 1922. A geographical study of the kangaroo rats of California. University of California Publications in Zoology. Vol. 24.

Holt, R.D. 1977. Predation, apparent competition, and the structure of prey communities. Theoretical Population Biology 12: 197-229.

Johnson, M.D. and Y.L. De León. 2015. Effect of an invasive plant and moonlight on rodent foraging behavior in a coastal dune ecosystem. PLoS ONE 10(2): e0117903. Doi:10.1371/journal.pone.0117903

Kauffman, M.J. and J.L. Maron. 2006. Consumers limit the abundance and dynamics of a perennial shrub with a seed bank. American Naturalist 168: 454-470.

Kelt, D.A. 1988. Dipodomys heermanni. Mammalian Species 323: 1-7.

Kenagy, G.J. 1973. Adaptations for leaf eating in the great basin kangaroo rat, Dipodomys microps. Oecologia 12: 383-412.

Kenagy, G.J. 1973. Daily and seasonal patterns of activity and energetics in a heteromyid community. Ecology 54: 1201-1219. 
Kerley, G. I.H., W.G. Whitford, and F.R. Kay. 1997. Mechanisms for the keystone status of kangaroo rats: graminivory rather than granivory? Oecologia 111:422-428.

Lockard, R.B. and J.S. Lockard 1971. Seed preference and buried seed retrieval of Dipodomys deserti. Journal of Mammalogy 52: 219-221.

Longland, W.S. 2007. Desert rodents reduce seedling recruitment of Salsola paulsenii. Western North American Naturalist 67: 378-383.

Longland, W.S., and M.V. Price. 1991. Direct observations of owls and heteromyid rodents: Can predation risk explain microhabitat use? Ecology 72: 2261-2273.

Love, R.M. 1948. Eight new plants developed for California ranges. California Agriculture. 2:7.

Mares, M. 1993. Desert rodents, seed consumption, and convergence. BioScience 43: 372-379.

McAdoo, J.K., C.C. Evans, B.A. Roundy, J.A. Young, and R.A. Evans. 1983. Influence of heteromyid rodents on Oryzopsis hymenoides germination. Journal of Range Management 36: 61-64.

Pearson, D.E., J.L. Hierro, M. Chiuffo and D. Villarreal. 2014. Rodent seed predation as a biotic filter influencing exotic plant abundance and distribution. Biological Invasions 16: 1185-1196.

Pearson, D.E., R.M. Callaway and J.L. Maron. 2011. Biotic resistance via granivory: establishment by invasive, naturalized, and native asters reflects generalist preference. Ecology 92: 1748-1757.

Pickart, A.J. 2000. Ehrharta calycina, Ehrharta erecta, and Ehrharta longiflora in: Bossard CC, JM Randall, and MC Hoshovsky (eds.) 2000. Invasive Plants of California's Wildlands. University of California Press Berkeley, CA 164-170.

Podolsky, R.H. and M.V. Price. 1990. Patch use by Dipodomys deserti (Rodentia: Heteromyidae): Profitability, preference, and depletion dynamics. Oecologia 83: 83-90.

Power, M.E., D. Tillman, J.A. Estes, B.A. Menge, W.J. Bond, L.S. Mills, G. Daily, J.C. Castilla, J. Lubchenco, and R.T. Paine. 1996. Challenges in the quest for keystones. BioScience 46: 609-620.

Price, M.V. 1983. Laboratory studies of seed size and seed species selection by heteromyid rodents. Oecologia 60: 259-263. 
Price, M., R.A. Correll. 2001. Depletion of seed patches by Merriam's kangaroo rats: are GUD assumption met? Ecology Letters 4:334-343.

Price, M.V. and W.S. Longland. 1989. Use of artificial seed patches by heteromyid rodents. Journal of Mammalogy 70: 316-322.

Randall, J.A. 1991. Mating strategies of a nocturnal, desert rodent (Dipodomys spectabilis) Behavioral Ecology and Sociobiology 28: 215-220.

Reichman, O.J. 1975. Relation of desert rodent diets to available resources. Journal of Mammalogy 56: 731-751.

Reichman, O.J. and K.M. Van De Graaff. 1973. Seasonal activity and reproductive patterns of five species of Sonoran desert rodents. American Midland Naturalist 90: 118-126.

Roest, A. I. (1991), Captive reproduction in Heermann's kangaroo rat, Dipodomys heermanni. Zoo Biol., 10: 127-137.

Schiffman, P.A. 1994. Promotion of exotic weed establishment by endangered giant kangaroo rats (Dipodomys ingens) in a California grassland. Biodiversity and Conservation 3: 524-537.

Schmidt-Nielsen K. 1964. Desert Animals: Physiological problems of heat and water. London: Clarendon Press.

Schroder, G.D. 1979. Foraging behavior and home range utilization of the Bannertail kangaroo rat (Dipodomys spectabilis). Ecology 60: 657-665.

Shier, D.M. and J.A. Randall. 2004. Spacing as a predictor of social organization in kangaroo rats (Dipodomys heermanni arenae) Journal of Mammalogy 85: 10021008 .

Shier, D.M. and J.A. Randall. 2007. Use of different signaling modalities to communicate status by dominant and subordinate Heermann's kangaroo rats (Dipodomys heermanni). Behavioral Ecology and Sociobiology 61:1023-1032.

Shier, D.M. and S.I. Yoerg. 1999. What footdrumming signals in kangaroo rats (Dipodomys heermanni). Journal of Comparative Psychology 113:66-73.

Stewart, G.R. and A.I. Roest. 1960. Distribution and habits of kangaroo rats at Morro Bay. Journal of Mammalogy 41: 126-129.

Tappe, D.T. 1941. Natural history of the Tulare kangaroo rat. Journal of Mammalogy 22; 117-148. 
Theimer, T.C., M.K. Sogge, E.G. Paxton. 2012, "Bird use of non-native tamarisk in the American Southwest: complexities, consequences, and changing perceptions", Bridging the Gap: Connecting People, Nature, and Climate. North America Congress for Conservation Biology. Oakland, CA, Oakland Convention Center.

Thompson, K.V., M. Roberts, W.F. Rall. 1995. Factors affecting pair compatibility in captive kangaroo rats, Dipodomys heermanni. Zoo Biology 14:317-330.

U.S. Air Force. 1996. Peacekeeper Rail Garrison and Small ICBM Mitigation Program, San Antonio Terrace, Vandenberg Air Force Base, California. Final report on the successful creation of wetlands and restoration of uplands. Unpublished report prepared by the Earth Technology Corporation, SAIC, and FLx for Department of the Air Force, Detachment 10, Space and Missile Systems Center, San Bernardino, CA.

U.S. Fish and Wildlife Service. 1999. Morro Bay Kangaroo Rat (Dipodomys heermanni morroensis) Draft Revised Recovery Plan. Portland, OR. 96 pp.

U.S. Fish and Wildlife Service. 2011. Morro Bay Kangaroo Rat (Dipodomys heermanni morroensis). 5-Year Review: Summary and Evaluation.

Valone, T.J. and J.S. Brown. 1989. Measuring patch assessment abilities of desert granivores. Ecology 70: 1800-1810.

Vander Wall, S.B., W.S. Longland, S. Pyare, and J.A. Veech. 1998. Cheek pouch capacities and loading rates of heteromyid rodents. Oecologia 113: 21-28.

Veech, J.A. 2001. The foraging behavior of granivorous rodents and short-term apparent competition among seeds. Behavioral Ecology 12: 467-474.

Villablanca, F. 2007. Morphological and Genetic Divergence of Morro Bay Kangaroo Rats. U.S. Fish and Wildlife Service and California Department of Fish and Game. Pp. 34.

Webster, D. B. 1962. A function of the enlarged middle-ear cavities of the kangaroo rat, Dipodomys. Physiological Zoology, 248-255.

Williams, D.F., and K.S. Kilburn. 1991. Dipodomys ingens. Mammalian Species 377: 17.

Wood, A. E. 1935. Evolution and Relationship of the Heteromyid Rodents: With New Forms from the Tertiary of Western North America. Carnegie Museum.

Yoerg, S.I. 1999. Solitary is not asocial: Effects of social contact in kangaroo rats (Heteromyidae: Dipodomys heermanni). Ethology 105:317-333. 
Yoerg, S.I. and D.M. Shier. 1997. Maternal presence and rearing condition affect responses to a live predator in kangaroo rats (Dipodomys heermanni arenae). Journal of Comparative Psychology 111:362-369.

Young, H.S., D.J. McCauley, R. Guevara, R. Dirzo. 2013. Consumer preference for seeds and seedlings of rare species impacts tree diversity at multiple scales. Oecologia 172: 857-867.

Zavaleta, E.S., R.J. Hobbs and H.A. Mooney. 2001. Viewing invasive species removal in a whole-ecosystem context. TRENDS in Ecology and Evolution 16: 454-459. 


\section{APPENDICES}

\section{Appendix A}

Table 1. Summary of the kangaroo rats marked and later detected across study sites. Site names with "+" indicate Veldt grass presence, and site names with "." indicate veldt grass absence. The total number of animals individually marked at each site (\# of Animals Marked), and the corresponding number of males and females is shown. The number of individually marked animals that were later detected in camera traps during seed-take trials (\# number of Animals Detected) at each site are shown, as is the corresponding number of males and females.
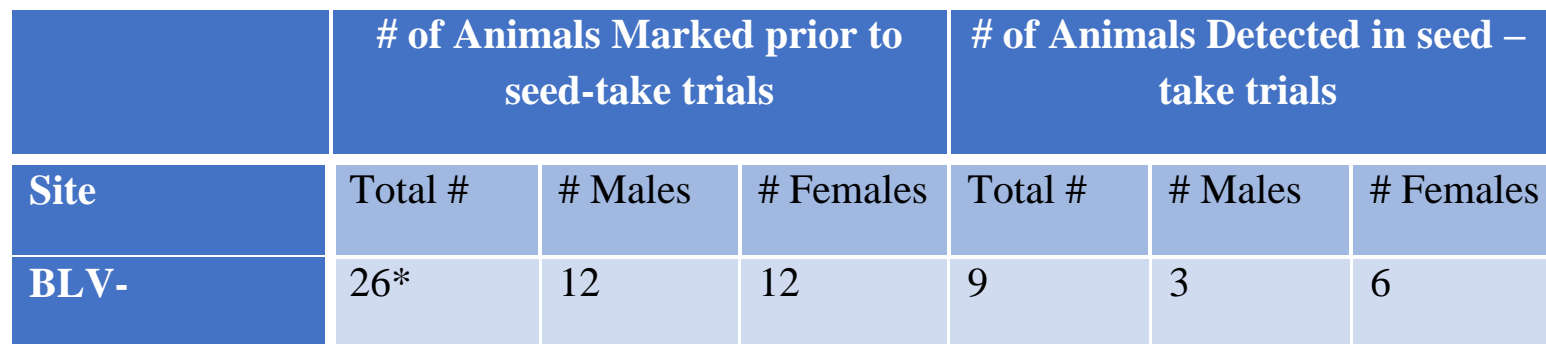

\begin{tabular}{|l|l|l|l|l|l|}
\hline Total \# & \# Males & \# Females & Total \# & \# Males & \# Females \\
\hline $26^{*}$ & 12 & 12 & 9 & 3 & 6 \\
\hline 3 & 1 & 2 & 3 & 1 & 2 \\
\hline $3 *$ & 2 & & 2 & 2 & 0 \\
\hline $5 *$ & 2 & 2 & 4 & 2 & 2 \\
\hline 8 & 4 & 4 & 1 & 1 & 0 \\
\hline
\end{tabular}

*Note sex of some individuals was unknown 
Table 2. Experimental design for seed-take trials including, locations, whether seedtake patches were in an area with $\left(V_{+}\right)$or without (V-) Veldt grass, seed-take trial dates, the average percent of the moon that was illuminated (percent visible), the number of kangaroo rats detected during each field trial, and the minimum spacing between seed-take patches ( $\mathrm{Y}$-maze with camera trap) placed in the field at the same time. One individual (denoted*) was detected on two trial dates at different stations.

\begin{tabular}{|c|c|c|c|c|c|}
\hline Site & $\begin{array}{l}\text { Date of } \\
\text { trial }\end{array}$ & $\begin{array}{l}\text { Percent of } \\
\text { Moon } \\
\text { Illuminated }\end{array}$ & Site Type & $\begin{array}{l}\# \\
\text { Marked } \\
\text { Animals } \\
\text { Detected }\end{array}$ & $\begin{array}{l}\text { Min } \\
\text { Distance } \\
\text { between } \\
\text { seed-take } \\
\text { patches }\end{array}$ \\
\hline \multirow[t]{2}{*}{ Black Lake } & \multirow{2}{*}{$\begin{array}{l}4 / 13 / 14- \\
4 / 18 / 14\end{array}$} & \multirow[t]{2}{*}{97.8} & V- & 4 & $10 \mathrm{~m}$ \\
\hline & & & V+ & 3 & $10 \mathrm{~m}$ \\
\hline \multirow[t]{2}{*}{ ODSVRA } & \multirow[t]{2}{*}{$\begin{array}{l}4 / 21 / 14- \\
4 / 26 / 14\end{array}$} & \multirow[t]{2}{*}{39.2} & V- & $4^{*}$ & $20 \mathrm{~m}$ \\
\hline & & & V+ & 1 & $25 \mathrm{~m}$ \\
\hline Black Lake & \multirow{2}{*}{$\begin{array}{l}\text { 4/28/14- } \\
5 / 3 / 14\end{array}$} & \multirow[t]{2}{*}{3.4} & V- & 3 & $15 \mathrm{~m}$ \\
\hline Callender & & & $\mathrm{V}+$ & 2 & $20 \mathrm{~m}$ \\
\hline ODSVRA & \multirow[t]{2}{*}{$\begin{array}{l}5 / 5 / 14- \\
5 / 10 / 14\end{array}$} & \multirow[t]{2}{*}{52} & V- & $1 *$ & $15 \mathrm{~m}$ \\
\hline Black Lake & & & V- & 2 & $15 \mathrm{~m}$ \\
\hline ODSVRA & $\begin{array}{l}5 / 12 / 14- \\
5 / 17 / 14\end{array}$ & 97.4 & V+ & 0 & $15 \mathrm{~m}$ \\
\hline
\end{tabular}


Table 3. Individual data for kangaroo rats used in laboratory seed choice/seed use trials. Capture locations, capture dates, sex, and seed consumption experiment dates, for all animals brought into captivity are shown.

\begin{tabular}{|c|c|c|c|c|c|}
\hline $\begin{array}{l}\text { Individual } \\
\text { ID }\end{array}$ & Site Type & $\begin{array}{l}\text { Trap } \\
\text { Date }\end{array}$ & Sex & $\begin{array}{l}\text { Number of Days } \\
\text { in Captivity } \\
\text { Prior to } 1^{\text {st }} \text { Trial }\end{array}$ & $\begin{array}{l}\text { Number of Days } \\
\text { in Captivity Prior } \\
\text { to } 2^{\text {nd }} \text { Trial }\end{array}$ \\
\hline 3202 & BLV- & $5 / 17 / 14$ & Male & 3 & 75 \\
\hline 3201 & BLV- & $5 / 17 / 14$ & Male & 3 & 75 \\
\hline 3131 & $\begin{array}{l}\text { Callender } \\
\mathrm{V}+\end{array}$ & $5 / 24 / 14$ & Female & 3 & 68 \\
\hline 3095 & BLV+ & $5 / 25 / 14$ & Male & 3 & 67 \\
\hline 3083 & BLV- & $5 / 25 / 14$ & Male & 3 & 67 \\
\hline 3213 & ODSVRAV+ & $6 / 1 / 14$ & Male & 3 & 61 \\
\hline 3267 & ODSVRAV+ & $6 / 1 / 14$ & Male & 3 & 61 \\
\hline 3247 & ODSVRAV- & $7 / 11 / 14$ & Female & 3 & 20 \\
\hline 3119 & ODSVRAV- & $7 / 11 / 14$ & Female & 3 & 20 \\
\hline 3172 & ODSVRAV+ & $7 / 11 / 14$ & Male & 3 & 20 \\
\hline
\end{tabular}


Table 4. Summary table of the number of kangaroo rats that visited seed-take patches in the field, the average number of visits and average number of visits involving take as a function of sex and site-type.

\begin{tabular}{|l|l|l|l|l|l|}
\hline Sex & Sample Size & $\begin{array}{l}\text { Number of } \\
\text { Animals } \\
\text { From Veldt }\end{array}$ & $\begin{array}{l}\text { Number of } \\
\text { Animals } \\
\text { From Non- } \\
\text { Veldt }\end{array}$ & $\begin{array}{l}\text { Average } \\
\text { Number of } \\
\text { Visits }\end{array}$ & $\begin{array}{l}\text { Average } \\
\text { Number of } \\
\text { Visits with } \\
\text { Take }\end{array}$ \\
\hline Females & 10 & 2 & 8 & 3.4 & 1.7 \\
\hline Males & 9 & 4 & 5 & 8.6 & 4 \\
\hline Total & 19 & 6 & 13 & & \\
\hline
\end{tabular}

Table 5. Summary table of the number of kangaroo rats that visited seed-take patches in the field by site type, with total number of visits, number of visits with handling time and total number of visits with take shown. Values for individuals are in parentheses.

\begin{tabular}{|l|l|l|l|l|}
\hline Site Type & $\begin{array}{l}\text { Number of } \\
\text { Individuals }\end{array}$ & $\begin{array}{l}\text { Total Number of } \\
\text { Visits (per } \\
\text { individual value) }\end{array}$ & $\begin{array}{l}\text { Total Number of } \\
\text { Visits with } \\
\text { Handling Time } \\
\text { (per individual } \\
\text { value) }\end{array}$ & $\begin{array}{l}\text { Total Number of Visits } \\
\text { with Take (per } \\
\text { individual value) }\end{array}$ \\
\hline Veldt & 6 & $34(5.66)$ & $11(1.83)$ & $18(3)$ \\
\hline $\begin{array}{l}\text { Non- } \\
\text { Veldt }\end{array}$ & 13 & $78(6)$ & $50(3.84)$ & $27(2.08)$ \\
\hline
\end{tabular}

Table 6. The number (percentage) of kangaroo rat individuals that took seed from seed-take patches. The habitat type and type of seed collected are shown.

\begin{tabular}{|l|l|l|l|}
\hline Total Individuals & 19 & Non-Veldt Habitat & Veldt Habitat \\
\hline $\begin{array}{l}\text { Collected Native } \\
\text { Seed }\end{array}$ & $12(63 \%)$ & 13 & 6 \\
\hline Collected Veldt Seed & $9(47 \%)$ & $8(61 \%)$ & $4(66 \%)$ \\
\hline $\begin{array}{l}\text { Collected Both Seed } \\
\text { Types }\end{array}$ & $5(26 \%)$ & $7(54 \%)$ & $2(33 \%)$ \\
\hline
\end{tabular}


Table 7. Artificial seed-take patches were placed in the field to test if $\boldsymbol{D}$.h. arenae would take Veldt grass (Ehrharta calycina). The dependent variables that were measured along with the independent variables are given. A repeated measures ANOVA was conducted using a split plot design in JMP, with individual as a fixed effect. The resulting F-statistics, degrees of freedom, and P-values are shown, p-values with an asterisk denote significant values.

\begin{tabular}{|c|c|c|c|c|}
\hline \multicolumn{5}{|c|}{ Dependent Variables } \\
\hline $\begin{array}{l}\text { Independent } \\
\text { Variables }\end{array}$ & $\begin{array}{l}\text { Manipulation } \\
\text { Time }\end{array}$ & $\begin{array}{l}\text { Average percent } \\
\text { of the patch } \\
\text { taken per visit }\end{array}$ & \# of visits & $\begin{array}{l}\text { \# of visits involving } \\
\text { take }\end{array}$ \\
\hline$\overline{\operatorname{Sex}}$ & $\begin{array}{l}F=1.252 \\
D f=15 \\
P=0.281\end{array}$ & $\begin{array}{l}F=5.608 \\
D f=15 \\
P=0.032\end{array}$ & $\begin{array}{l}F=4.874 \\
D f=15 \\
P=0.043\end{array}$ & $\begin{array}{l}F=0.870 \\
D f=15 \\
P=0.366\end{array}$ \\
\hline Site Type & $\begin{array}{l}F=0.318 \\
D f=15 \\
P=0.581\end{array}$ & $\begin{array}{l}F=0.329 \\
D f=15 \\
P=0.575\end{array}$ & $\begin{array}{l}F=1.178 \\
D f=15 \\
P=0.295\end{array}$ & $\begin{array}{l}F=0.121 \\
D f=15 \\
0.733\end{array}$ \\
\hline Sex*Site Type & $\begin{array}{l}F=0.140 \\
D f=15 \\
P=0.714\end{array}$ & $\begin{array}{l}F=0.054 \\
D f=15 \\
P=0.819\end{array}$ & $\begin{array}{l}F=0.005 \\
D f=15 \\
P=0.946\end{array}$ & $\begin{array}{l}F=1.592 \\
D f=15 \\
P=0.226\end{array}$ \\
\hline Seed Type & $\begin{array}{l}F=1.113 \\
D f=15 \\
P=0.308\end{array}$ & $\begin{array}{l}F=3.251 \\
D f=15 \\
P=0.092\end{array}$ & $\begin{array}{l}F=0.858 \\
D f=15 \\
P=0.369\end{array}$ & $\begin{array}{l}F=0.532 \\
D f=15 \\
P=0.477\end{array}$ \\
\hline Sex*Seed Type & $\begin{array}{l}F=0.955 \\
D f=15 \\
P=0.344\end{array}$ & $\begin{array}{l}F=3.151 \\
D f=15 \\
P=0.097\end{array}$ & $\begin{array}{l}F=0.074 \\
D f=15 \\
P=0.790\end{array}$ & $\begin{array}{l}F=0.033 \\
D f=15 \\
P=0.858\end{array}$ \\
\hline $\begin{array}{l}\text { Site } \\
\text { Type*Seed } \\
\text { Type }\end{array}$ & $\begin{array}{l}F=0.399 \\
D f=15 \\
P=0.537\end{array}$ & $\begin{array}{l}F=1.619 \\
D f=15 \\
P=0.223\end{array}$ & $\begin{array}{l}F=0.305 \\
D f=15 \\
P=0.589\end{array}$ & $\begin{array}{l}F=0.033 \\
D f=15 \\
P=0.858\end{array}$ \\
\hline $\begin{array}{l}\text { Sex*Site } \\
\text { Type*Seed } \\
\text { Type }\end{array}$ & $\begin{array}{l}F=0.823 \\
D f=15 \\
P=0.379\end{array}$ & $\begin{array}{l}F=2.713 \\
D f=15 \\
P=0.120\end{array}$ & $\begin{array}{l}F=0.417 \\
D f=15 \\
P=0.528\end{array}$ & $\begin{array}{l}F=0.532 \\
D f=15 \\
P=0.477\end{array}$ \\
\hline
\end{tabular}


Table 8. For kangaroo rats with two sequential visits to the same seed-take patch in the same night, a Wilcoxon Signed Rank test was performed to examine whether there was a difference between the first and second experience for handling time, collecting time, or percent of available seed collected by sex and site type of origin. P-values for Wilcoxon Signed Rank test are shown.

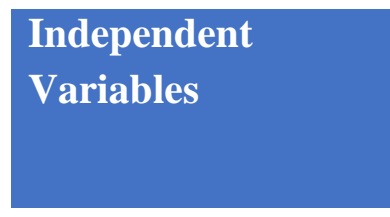

Females

Males

Non-Veldt

Veldt
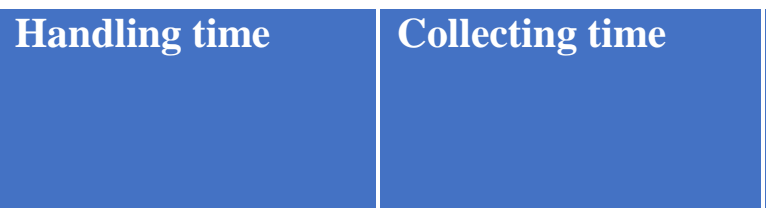

0.250

0.656

0.523

0.250
0.625

1.000

0.625

1.000
Average Percent of the Patch Taken per Visit

0.625

1.000

0.625

1.000 


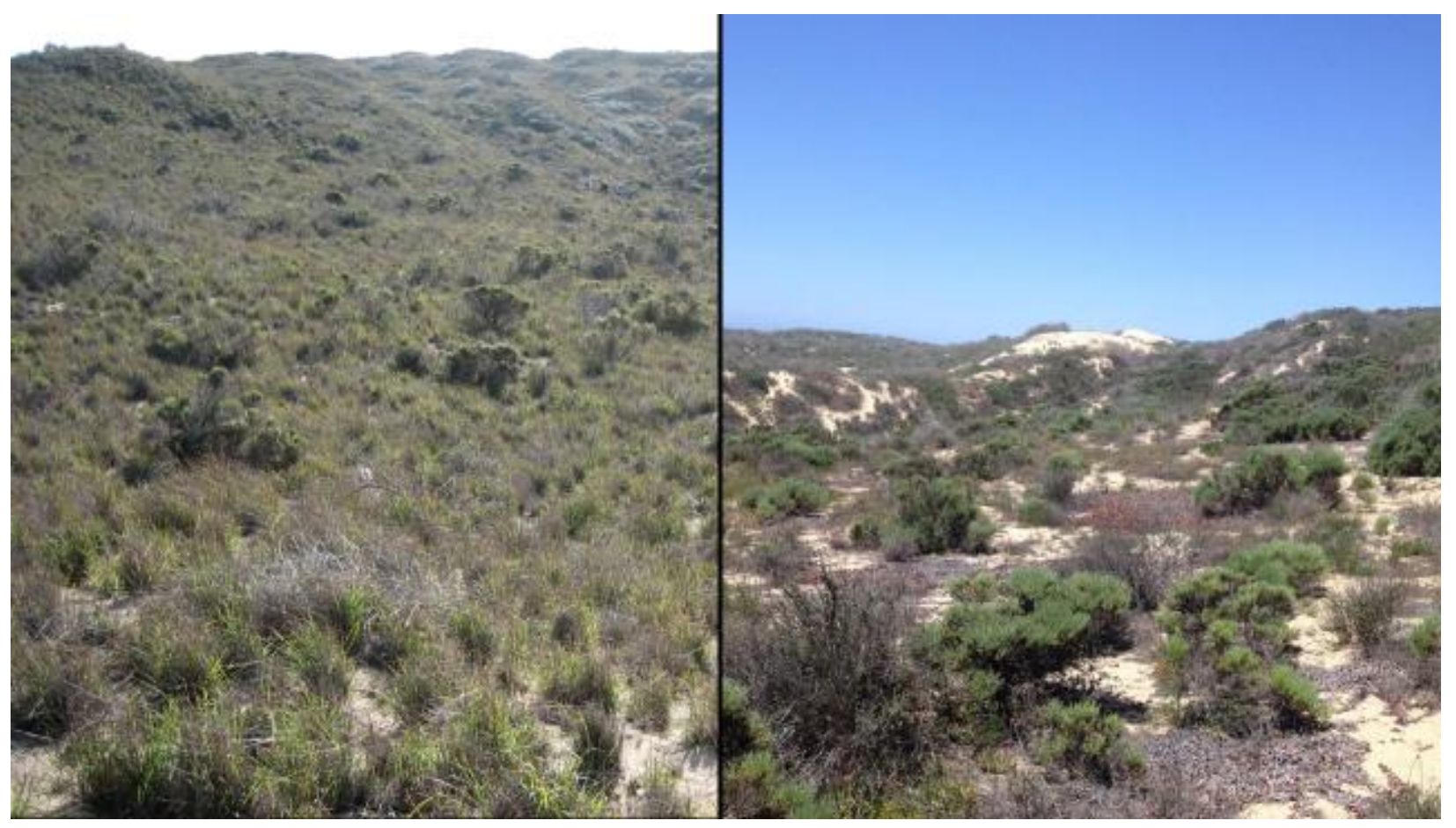

Figure 1. Example study sites with of Veldt invading coastal scrub (left, ODSVRAV+) and non-invaded coastal scrub (right, ODSVRAV-). 


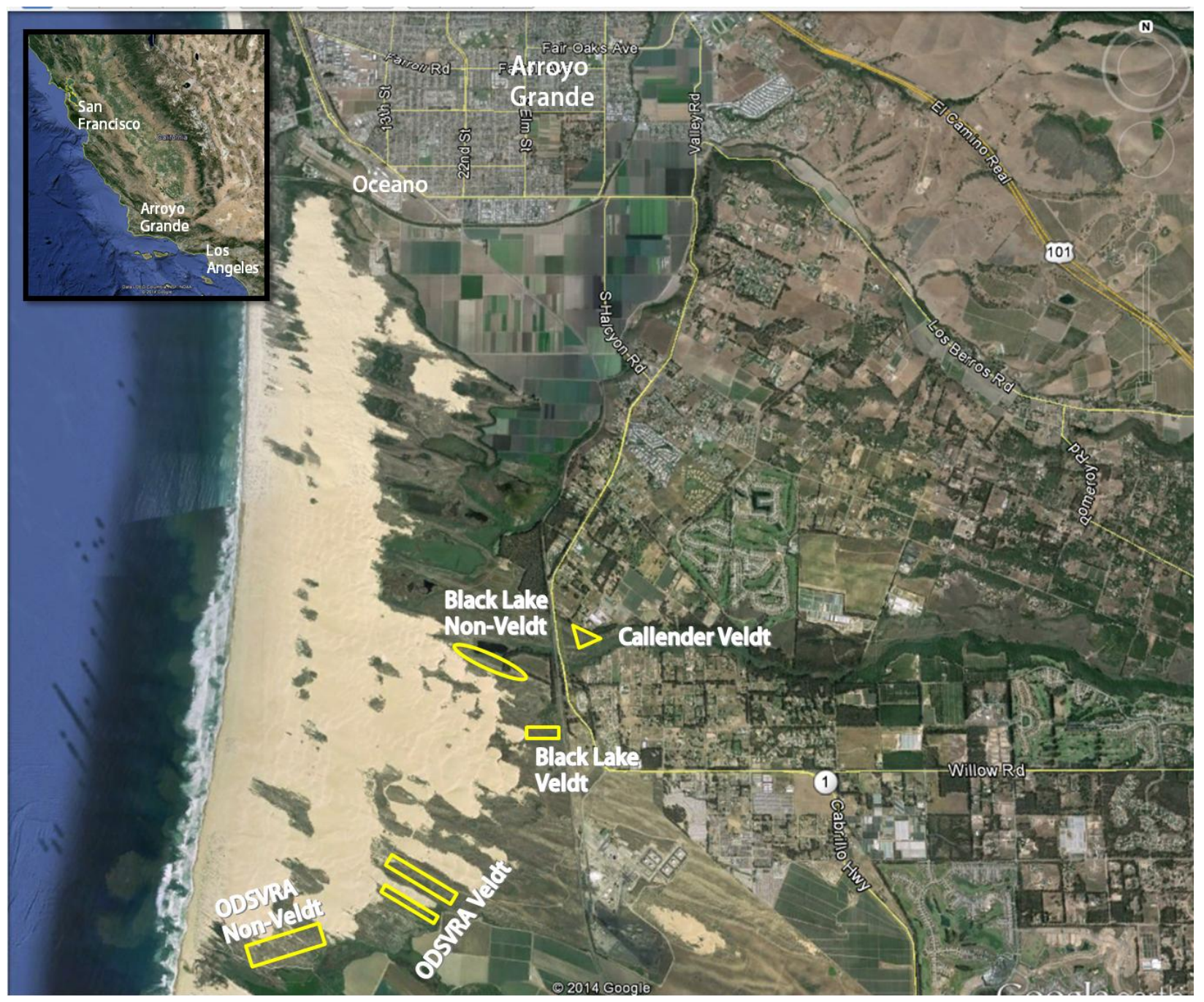

Figure 2. Location of field sites use for seed-take trials. The dune complex is composed of contiguous dune system comprised of the Pismo, Oceano, Nipomo, and Guadalupe dunes. Habitats vary from coastal dune scrub communities without Veldt grass present to coastal dune scrub communities invaded by Veldt grass. See Figures 2 and 3 for specific locations used for seed trials. 


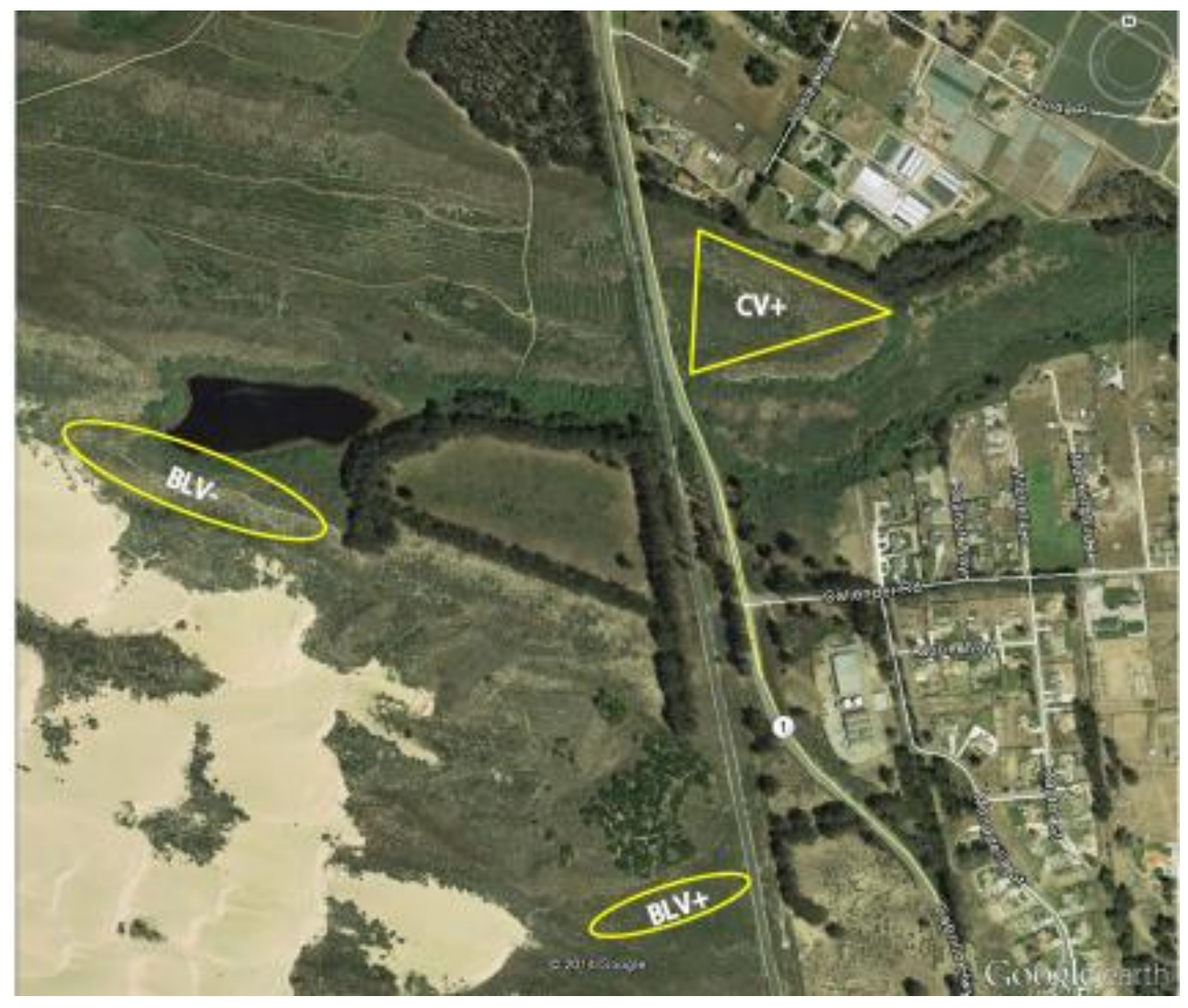

Figure 3. Map showing the three study sites in Black Lake Canyon (Land Conservancy of San Luis Obispo). Acronyms indicate Black Lake Non-Veldt (BLV-), Black Lake Veldt (BLV+), and Callender Veldt (CV+). Refer to Figure 2 for georeference location within the state of California. 


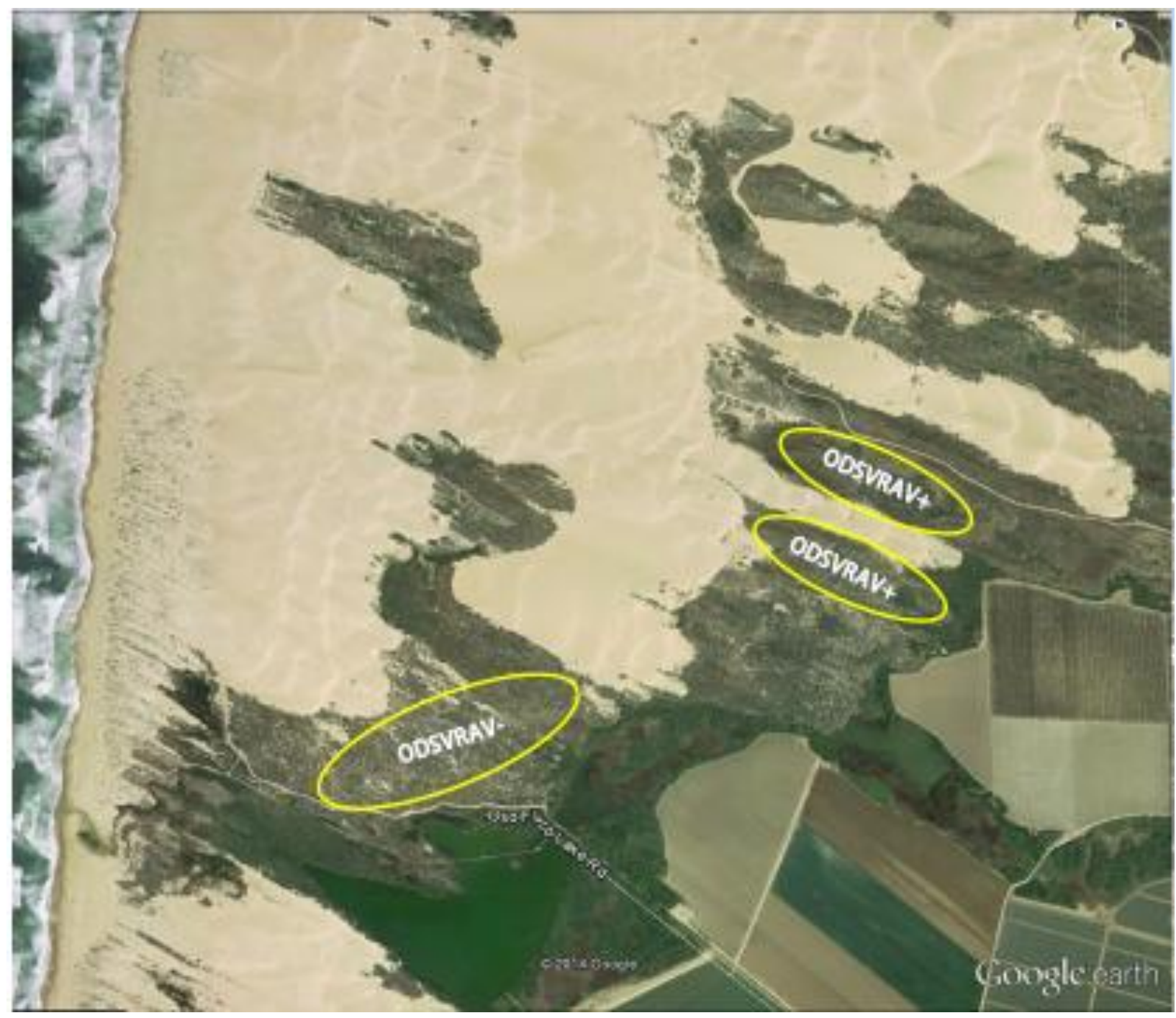

Figure 4. Map showing the two Oceano Dunes State Vehicular Recreation Area (ODSVRA) study sites: ODSVRA Non-Veldt (ODSVRAV-) and ODSVRA Veldt (ODSVRAV+). Refer to Figure 2 for georeference location within the state of California. 


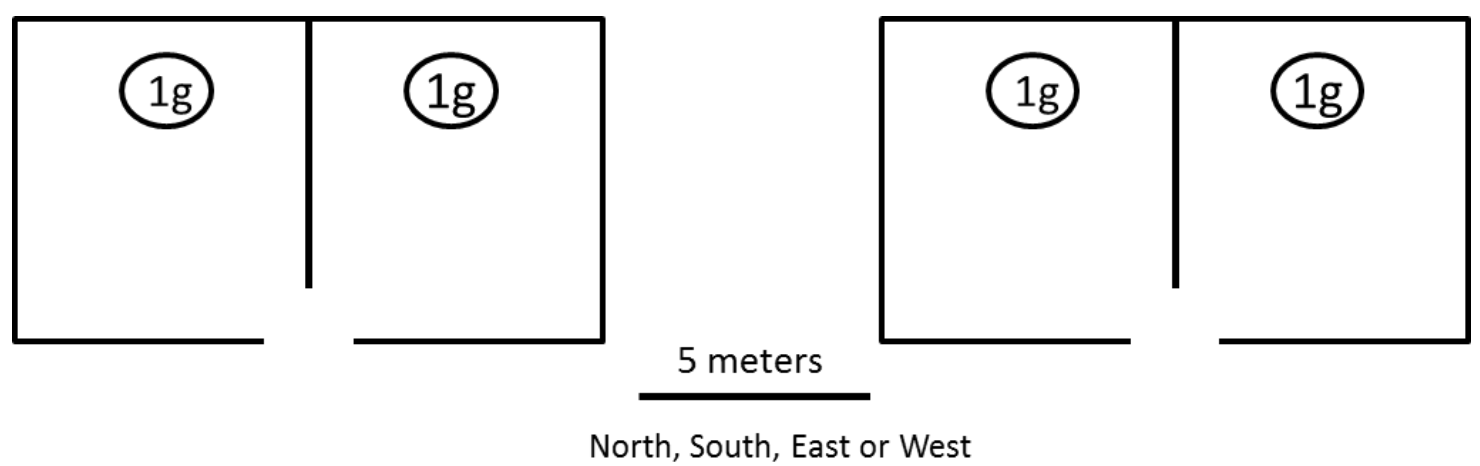

Figure 5. Seed-take patches consisted of paired seed-take boxes, with $1 \mathrm{~g}$ of seed (Veldt grass or Native seed cocktail) assigned randomly, each night, to each side, separated by 5 meters and monitored with an overhead game camera for 5 consecutive nights.

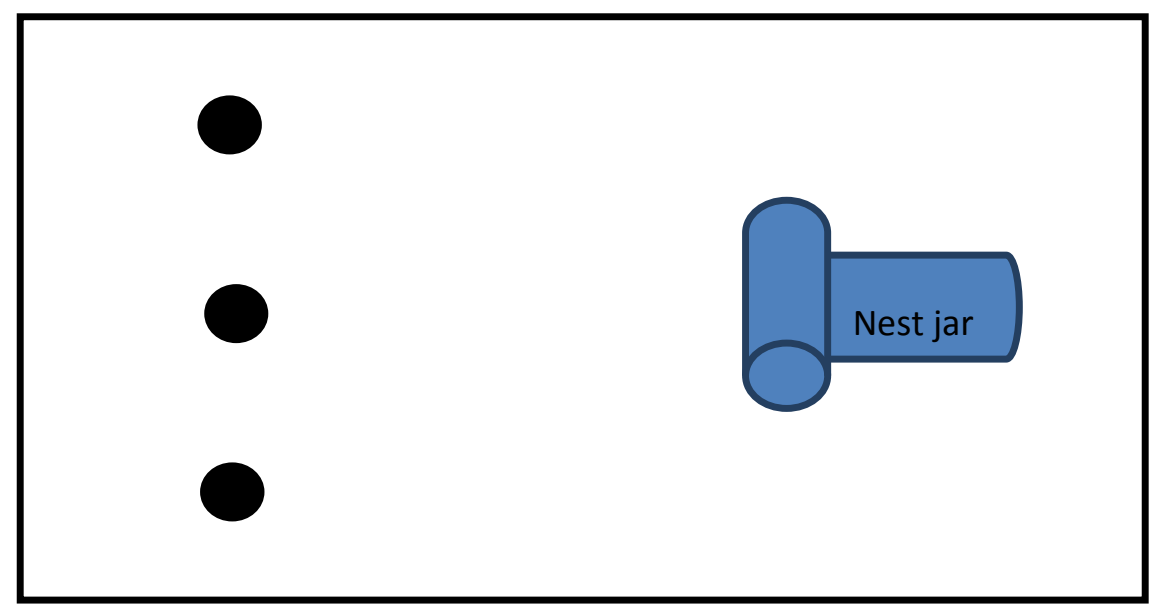

Figure 6. Diagram of home cage in which seed take trials took place. Black circles represent $1 \mathrm{~g}$ piles of either Veldt grass seed, millet, or sunflower seeds. The placement order (as shown here) of Veldt, millet, or sunflower seed was randomly selected every night. 
